\title{
Inkjet based 3D Printing of bespoke medical devices that resist bacterial biofilm formation
}

†Yinfeng He ${ }^{1}$, †Belen Begines ${ }^{2}$, Jeni Luckett ${ }^{4}$, Jean-Frédéric Dubern ${ }^{4}$, Andrew L. Hook ${ }^{3}$,

Elisabetta Prina ${ }^{3}$, Felicity R.A.J. Rose ${ }^{3}$, Christopher J. Tuck ${ }^{1}$, Richard J.M. Hague ${ }^{1}$, Derek J.

Irvine $^{1}$, Paul Williams ${ }^{4}$, Morgan R. Alexander ${ }^{3 *}$ and Ricky D. Wildman ${ }^{1 *}$

${ }^{1}$ Faculty of Engineering, University of Nottingham, University Park, Nottingham, NG7 2RD, United

Kingdom

${ }^{2}$ Department of Organic and Medicinal Chemistry, School of Pharmacy, University of Seville, Seville,

41012, Spain

${ }^{3}$ School of Pharmacy, University of Nottingham, University Park, Nottingham, NG7 2RD, United

Kingdom

${ }^{4}$ National Biofilm Innovation Centre, University of Nottingham Biodiscovery Institute, School of Life

Sciences, University of Nottingham, University Park, Nottingham, NG7 2RD, United Kingdom

$\dagger$ These authors contributed equally to this work.

*Corresponding Author

Keywords: Biofilms, Cell instructive behaviour, Medical Devices, Inkjet, 3D Printing

*correspondence to: Ricky.Wildman@nottingham.ac.uk ; Morgan. Alexander@nottingham.ac.uk 


\begin{abstract}
We demonstrate the formulation of advanced functional 3D printing inks that prevent the formation of bacterial biofilms in vivo. Starting from polymer libraries, we show that a biofilm resistant object can be $3 \mathrm{D}$ printed with the potential for shape and cell instructive function to be selected independently. When tested in vivo, the candidate materials not only resisted bacterial attachment but drove the recruitment of host defences in order to clear infection. To exemplify our approach, we manufacture a finger prosthetic and demonstrate that it resists biofilm formation - a cell instructive function that can prevent the development of infection during surgical implantation. More widely, cell instructive behaviours can be 'dialled up' from available libraries and may include in the future such diverse functions as the modulation of immune response and the direction of stem cell fate.
\end{abstract}




\section{Introduction}

Medicine is moving towards meeting the needs of individual patients through patient stratification and personalisation. This can arise in many forms e.g. for implanted medical devices, through tailoring of shape, of material and of function, each tuned to the specific needs of the patient. One method to achieve this is through 'additive manufacturing' (AM) or '3D Printing (3DP)' ${ }^{[1-3]}$ but it requires the identification and scale-up of 3D printable materials or formulations that have the required functional performance. We propose a strategy that allows us to formulate materials with cell instructive properties that adds an additional lever of personalisation to current 3D printed devices. We exemplify this strategy by testing the efficacy of our formulations in vitro, in vivo and by manufacturing a bespoke finger joint prosthetic that demonstrates resistance to bacterial biofilm formation. This choice of cellinstructive function is inspired by the need to prevent medical device associated infections ${ }^{[4-7]}$. Studies have shown that 1 to $5 \%$ of implanted prostheses become colonized ${ }^{[8,9]}$ with biofilms formed by pathogens such as Pseudomonas aeruginosa and Staphylococcus aureus resulting in poor clinical outcomes ${ }^{[10]}$. Such biofilms are refractory to both antibiotic therapy and to clearance by host immune defence mechanisms leading to chronic infections and device failure. Thus, the use of personalised prosthetics brings with it a need to prevent microbial infection. Whilst our demonstrator focuses on infection prevention, our manufacturing strategy is agnostic with respect to the cell instructive functionality and material libraries.

The chosen demonstrator device differs in approach to other anti-microbial devices, such as those blending antibiotics into the material or through surface modification ${ }^{[11-18]}$. These approaches have multiple issues including coating delamination and cracking in the aggressive implant service environment ${ }^{[16]}$, localized cytotoxicity from anti-microbial coatings ${ }^{[16]}$, active compound depletion $^{[17,18]}$, and most crucially, potential selection for anti-microbial resistance resulting from the selective pressures that antimicrobial killing strategies impose ${ }^{[19]}$. Here we exploit acrylate monomers, previously identified to prevent bacterial biofilm formation ${ }^{[20-22]}$ and use these as the basis for inks for 
inkjet based 3D printing (IJ3DP), an AM technique whose strengths come into play when there is a need for industrial scalability, high resolution, and multi-material manufacture. A biofilm prevention strategy reduces the evolutionary pressures that drive the development of antimicrobial resistance. The biofilm surface coverage on polymer samples was reduced by $99 \%$ compared with those on silicone rubber for diverse multi-antibiotic resistant pathogens including $P$. aeruginosa, $S$. aureus Escherichia coli, Klebsiella pneumoniae, Enterococcus faecalis and Proteus mirabilis ${ }^{[22,23]}$. Here, we present a novel approach that shows how the candidate materials identified from such a screen can be adapted to create formulations suitable for IJ3DP and demonstrate that these formulations are effective in vitro and in vivo in a foreign body infection model. We also ascertained that the mechanical and cell instructive performance of the materials is intimately tied to the degree of polymerization during printing and that there was no evidence of bacteria being killed through contact with the material or the leaching of any toxic residuals.

This approach, illustrated graphically in Fig. 1, takes materials from a previously published polymer library based on a screening for resistance to bacterial attachment and biofilm formation. We assessed candidates from the library for their capacity for consistent and reliable deposition from an ink jet print head. Formulations showing promise were used to create specimens that were characterised through a series of tests that examined: 1. level of uncured acrylates, 2. mechanical properties, 3. bacterial biofilm formation and 4. cytotoxicity towards bacterial cells. Since a potential application is to produce devices that may be used in a clinical context, we also investigated their mammalian cell cytotoxicity (following ISO 10993 guidelines) as well as in vivo biofilm inhibition performance tested in a mouse infection model. Thus, the formulations with the most promising performance were identified, used to produce concept devices by IJ3DP and challenged to understand their efficacy following manufacturing. 


\section{Results}

Using published lists of materials resistant to bacterial attachment we selected suitable candidates first using printability as a guide ${ }^{[24]}$, based on physical characteristics such as viscosity and surface tension, screening out those materials that were outside the range commonly accepted as 'printable' for inkjet. A trial printing of the remaining materials was then conducted to determine the reliability of printing and whether the materials would cure on our printing configuration. From this we selected two materials that showed the greatest promise for successful printing and proceeded to optimise the formulations ready for scale up ${ }^{[25-28]}$ (Supplementary Table S1): tricyclo[5.2.1.02,6]decanedimethanol diacrylate (TCDMDA) and ethylene glycol dicyclopentenyl ether acrylate (EGDPEA). Sixteen formulations were then investigated where the photoinitiator and the candidate monomers were combined covering a breadth of utility in different environments and potential reaction speeds (Supplementary Table S2) as both could influence the product performance ${ }^{[22,29-31]}$. Both Norrish type I (nitrogen environment) and Norrish type II (air environment) initiators were evaluated with respect to compatibility of the formulations when processing in different environments. A series of tests on each of our formulations were conducted to understand the performance of our 3D printed constructs in vitro and in vivo.

\section{Bacterial Biofilm Formation on Polymer Cuboid Arrays}

To determine whether printed samples retained their desired biofilm resistance, samples were printed using a laboratory-based inkjet printer. For each formulation, the printed samples consisted of a series of 24 cuboid arrays (2000 x $2000 \times 100 \mu \mathrm{m}^{3}$ each) (Fig. 2A) on polystyrene slides. P. aeruginosa biofilm surface coverage on the polymers was quantified after culturing for $72 \mathrm{~h}$. All the inkjet printed and cured poly-EGDPEA and poly-TCDMDA surfaces showed low biofilm surface coverage when compared with the silicone rubber control (Appleton Woods medical grade tubing). In previous work, poly-EGDPEA and poly-TCDMDA samples were prepared by monomer casting then curing and 
showed significant biofilm resistance, resulting in low $P$. aeruginosa biofilm coverages of $4.0 \% \pm 1.5 \%$ and $2.3 \% \pm 1.3 \%$ respectively ${ }^{[21]}$. The poly-EGDPEA and poly-TCDMDA made from inkjet printable formulations in this study showed a bacterial coverage of $3.0 \pm 0.9 \%$ and $3.3 \% \pm 1.2 \%$ respectively compared with $>30 \%$ for silicone (Fig. 2A), suggesting the performance of the IJ3DP samples was not statistically significantly different from those that had been cast and photopolymerized $(p=0.26$ and $p$ $=0.27$ ) and indicates that both materials retained their ability to prevent bacterial biofilm formation after IJ3DP.

Specimens formed using formulations containing higher concentrations of photoinitiator were found to result in lower bacterial biofilm coverage. For example, the bacterial surface coverage on the polyTCDMDA decreased from $8.2 \% \pm 3.2 \%$ to $0.2 \% \pm 0.1 \%$ when going from 0.5 wt $\%$ to 4 wt $\%$ DMPA initiator concentration. This reduction in biofilm coverage is attributed to higher conversion of polymer, suggesting the material's ability to resist biofilm formation is enhanced as conversion is increased. The alternative explanation that the increased photoinitiator concentration correlates with cytotoxicity of the material towards bacteria was ruled out using bacterial growth assays that are presented in Fig. 6A and Supplementary Fig. S4.

\section{Mechanical Performance Assessment}

The two materials selected for scale up were chosen in part due to their likely difference in mechanical properties, allowing a range of moduli to be accessed. The elastic moduli of the printed specimens were determined using dynamic mechanical analysis (DMA), to identify the relationships between the moduli and the composition. Strip specimens with dimensions of $5 \times 20 \times 1 \mathrm{~mm}^{3}$ were printed and tested in tension mode at room temperature (Fig. 2B). The mechanical performance of the printed samples was intimately linked to the photoinitiator concentration, and this effect was pronounced when the DETX initiator was used (usually used for 'in air' printing). The variation in photoinitiator concentration led to a modulus for poly-EGDPEA ranging from $0.2 \mathrm{MPa}$ to $180 \mathrm{MPa}$, while for poly- 
TCDMDA it ranged between $1.4 \mathrm{GPa}$ to $2.1 \mathrm{GPa}$. As anticipated, use of poly-TCDMDA and polyEGDPEA results in a significant separation in the ranges of moduli accessible (Fig. 2B), offering the opportunity to exploit the materials for a range of mechanical requirements such as when integrating with tissues as diverse as cartilage and cancellous bone ${ }^{[32,33]}$.

\section{Mammalian Cell Cytotoxicity and Attachment}

In this study, cytotoxicity assays for mammalian cells (using 3 T3 fibroblasts) were conducted using inkjet printed $5 \times 5 \times 1 \mathrm{~mm}^{3}$ cuboid samples (Fig. $3 \mathrm{~A}$ and B), following the guidelines presented in ISO $10993^{[34]}$ and detailed in the methods section. These tests were then used as a guide to whether printed constructs could support mammalian cell attachment and proliferation and as a first test of whether these materials could be used safely within the body.

Four sets of samples were considered to have sufficiently low cytotoxicity levels, thus rendering them as appropriate for use. Conditioned media samples from poly-TCDMDA-DETX-4 and polyTCDMDA-DMPA-4 were the only samples not to exhibit cytotoxicity at any time point, showing lactate dehydrogenase (LDH) levels similar to those of the control (Fig. 3D). Samples from polyEGDPEA-DMPA-4 and poly-TCDMDA-DMPA-1 showed cytotoxicity over three days, which reduced on subsequent time points. The pattern of photoinitiator content, monomer conversion (discussed in the following section) and cytotoxicity suggests that leaching of residual monomer leads to cytotoxicity, but in the case of EGDPEA-DMPA-4 and poly-TCDMDA-DMPA-1 these are cleared over a timescale of 5 days. All other samples showed either no improvement over the test period, or a highly cytotoxic response indicating that these formulations would be inappropriate for clinical use. Supporting results were obtained using the complementary 'Presto Blue' cell viability assay (Fig. S3). Further attachment testing (see methods section) indicated that $3 \mathrm{~T} 3$ cells attached and proliferated when cultured on poly-EGDPEA-DMPA-4, poly-TCDMDA-DETX-4, poly-TCDMDA-DMPA-1 and poly-TCDMDA-DMPA-4 surfaces (Fig. 3C). Of these, the metabolic activity of cells (determined 
using the Presto Blue assay) was highest on poly-TCDMDA-DETX-4 and poly-TCDMDA-DMPA-4

(Fig. 3E), closely matching the trends observed for the conditioned cytotoxicity assays.

\section{Spectroscopic Assessment of Curability}

In the above assays, it was hypothesised that the biocompatibility and modulus of the printed material as well as biofilm resistance were influenced by the level of monomer conversion. To investigate this and quantify the relationships, Attenuated Total Reflectance-Infrared Spectroscopy (ATR-IR) was used to determine the residual acrylate content of the films in order to understand whether there was a correlation between photoinitiator concentration, level of conversion and consequently, specimen performance.

Samples were prepared by inkjet printing cuboids of size $5 \times 5 \times 0.2 \mathrm{~mm}^{3}$ thickness. Fig. 4 shows the ATR-IR spectra for polymer samples as a function of the initiator concentration. In the ATR-IR test, the characteristic peak at $810 \mathrm{~cm}^{-1}$ (C-H bond out-of-plane bending vibration of the alkene group) indicates the relative amount of unreacted residual alkene group $(\mathrm{C}=\mathrm{C})$. For both initiators, the concentration of the residual $\mathrm{C}=\mathrm{C}$ reduced with increasing initiator concentration, consistent with increased conversion during printing. The relationship between the level of conversion and polymer performance was assessed using the Pearson correlation coefficient (Supplementary Fig.S1). For polyEGDPEA, the Pearson correlation coefficient between residual alkene groups and mechanical performance, biofilm coverage and cytotoxicity reached $0.82,0.69$ and 0.86 respectively; while for poly-TCDMDA, these values are $0.70,0.74$ and 0.92 , thereby confirming the strong link between the residual monomer quantity and key performance measurements.

Combining the correlation analysis for biofilm coverage, mammalian cell cytotoxicity, mechanical performance and level of conversion shows how the performance of printed samples can be optimised by ensuring that all these design criteria are met. 


\section{In Vitro and in Vivo Assessment of the Biofilm Resistance of the Printed Structures}

Two ink formulations (poly-TCDMDA-DMPA-4 and poly-TCDMDA-DETX-4) were chosen for further assessment owing to their superior performance across our range of measures. Hemi-cylindrical specimens ( $7 \mathrm{~mm}$ in length and $2 \mathrm{~mm}$ in diameter) were printed, matching the dimensions of our control samples, and also enabling sample delivery via a trocar needle in subsequent in vivo mouse studies. The viability of $P$. aeruginosa and $S$. aureus in contact with the printed specimens was also tested in vitro to ensure that the reduction in biofilm formation was due to colonisation resistance rather than toxicity associated with the material. These experiments revealed no loss of bacterial cell viability (as quantified via intracellular adenosine triphosphate (ATP) levels) during growth in the presence of the candidate samples (Fig. 5A) nor on a printed neopentyl glycol diacrylate (NGPDA) structure that promotes the formation of biofilms as a control polymer ${ }^{[20]}$. Since no reduction in bacterial viability was observed for bacteria colonizing the positive control, we can conclude that the material itself or any potential residuals in the structure printed by poly-TCDMDA-DMPA-4 and poly-TCDMDADETX-4, are not responsible for the lack of biofilm formation. Planktonic bacterial growth experiments (Supplementary Fig.S4) were consistent with the ATP assays and comparable with those in the presence of the NGPDA control.

Quantification of biofilm biomass and the corresponding confocal microscope images are shown in Fig. 5B, which demonstrate the considerable reduction in biofilm biomass observed for both pathogens on the poly-TCDMDA-DMPA-4 and poly-TCDMDA-DETX-4 formulations compared with the polyNGPDA control device as well as against sample from a commercial silicone rubber finger joint product (OSTF-0, size 0, Osteotec Ltd.) (Fig. 5B).

To understand the printed device's performance in a more complex host environment, in vivo infection experiments were carried out using a murine subcutaneous foreign body implant infection model (Fig.5C). After 4 days of post-surgical recovery, mice were inoculated with a bioluminescent strain of P. aeruginosa and the live infected animals imaged daily over 5 days (day 5 to day 9 from implanting; 
day 0 to day 4 after bacterial inoculation; Fig. 5 D and E), a period over which infection becomes providing $P$. aeruginosa can colonize the implanted device. Light emission from the bioluminescent pathogen demonstrated the presence of metabolically active bacteria at the infection site for all samples at bacterial inoculation day 0 (Fig. $5 \mathrm{D}$ and E). In contrast to the sustained light output indicative of bacterial colonization of the silicone implant, both poly-TCDMDA-DMPA-4 and poly-TCDMDADETX-4 formulations showed little bioluminescence ( $>3$ orders of magnitude reduction) consistent with resistance to bacterial attachment in vivo. This finding was confirmed by ex vivo analysis of the implants and the tissues surrounding the implants after their removal from the mice and re-imaging (Fig. $5 \mathrm{D}$ and E). In contrast to the TCDMDA formulations, the silicone rubber control showed significantly higher bioluminescence consistent with bacterial biofilm formation that also acts as a reservoir for sustaining infection within the interstitial tissues surrounding the implant.

In addition, qualitative imaging of the implants using immunohistochemical staining with antibodies raised against $P$. aeruginosa cells and with the fluorescent dye, FM1-43 (as a marker for host cell and bacterial membranes) revealed evidence of a robust host response and the presence of P. aeruginosa cells on both TCDMDA formulations (Supplementary Fig.S5). Given the lack of bioluminescence from such samples, these bacteria are dead, killed via a productive, antibacterial host response since the TCDMDA formulations per se are not bactericidal (Fig. 5A and Fig. S5). In contrast, the host defences were unable to kill the $P$. aeruginosa biofilm colonizing the silicone implant given the in vivo bioluminescence and ex vivo antibody labelling of the bacterial cells (Supplementary Fig. S4). This shows that not only do the devices retain their resistance to bacteria biofilm formation but also drive a productive host response that clears the infecting bacteria.

\section{Exemplar 3D Printed Biofilm Resistant FingerJoint Prosthetic}

To demonstrate that a 3D printed functional device could be realised we chose to manufacture a biofilm resistant finger joint prosthetic using ink jet 3D printing (Fig. 6A) ${ }^{[35,36]}$. Finger joint prosthetics were 
printed 1:1 relative to a commercial product using the best performing ink formulations for each monomer (TCDMDA-DMPA-4 and EGDPEA-DMPA-4). The platform used was identical to that used to produce specimens in previous studies, with a typical manufacturing time of around $4 \mathrm{~h}$. The dimension of the printed device was measured from the SEM images and compared with the CAD design (Supplementary Fig. S2). Optimisation of the manufacturing process is needed to ensure such devices could be taken forward for human use, but here we demonstrate that such a route is viable and reliable from the manufacturing aspect.

To check if geometry would impact the functional performance, samples reduced to $1 / 10$ of the original dimensions, were printed and tested in vitro. The change in dimension allowed biomass assessment under full view when assessing with fluorescent confocal microscope. The distribution of the $P$. aeruginosa and $S$. aureus biofilms that form on the devices confirmed the cell instructive property was retained (Fig. 6B). 


\section{Discussion}

This work has uncovered a series of findings that point towards the reliable manufacturing of cellinstructive structures via IJ3DP. With the advances in high throughput technologies, materials libraries offering diverse functions are becoming widely available ${ }^{[21-23,37]}$. It is not trivial, however, to go from an idealized screening approach to materials usable within a manufacturing setting. A key element of the approach outlined has been to establish optimized formulations able to support IJ3DP. In this work, we used a laboratory based single material printing system (Dimatix DMP-2830) with 16 nozzles. On this system, the identified formulations were stable and reliable during printing (Fig. 6C), capable of consistent printing of at least $8 \mathrm{~h}$ (the longest print run employed) with no nozzle blockage observed. In the future, this work could be translated to commercial inkjet printing systems that routinely employ multiple printheads containing 1024 nozzles or more, which would result in a throughput at least 14 times greater and with the potential to deploy support structures ${ }^{[38]}$ and therefore more complex geometries. This reliable printing allowed for the manufacture of multiple samples designed for assessment of important characteristics relating to product function. In the case chosen, such a product would need to be safe, meet specified mechanical requirements, and be functional (both structurally and cell instructive). Through a combination of screening to identify candidate formulations and optimization to ensure reliable printing and optimal performance, we were able to direct our activity towards the production of a component that would show high efficacy within the in vivo environment. Whilst other longer term host response tests will be required in order to complete the journey towards use in the clinic, our results show that the cell-instructive performance of our selected and optimized formulation are highly promising in an in vivo infection model, a critical step towards acceptance. In addition, our choice of manufacturing modality allows for personalization - our experiments utilize a range of shapes and sizes all created with the same platform all supporting our conclusion of material efficacy, and for potential scale up to industrial levels of throughput. 
In conclusion, this work demonstrates that advanced cell instructive properties may be incorporated into the production of bespoke medical devices. The materials that we have identified can be employed as feedstock for IJ3DP and that our comprehensive set of in vitro and in vivo tests confirm the key biofilm resistant property is retained throughout the manufacturing process. Interestingly, our analysis reveals that our selected materials play a previously unobserved role in recruiting host defences that clears the infecting bacteria and prevents biofilm maturation, an exciting finding that deserves future investigation. Whilst the exemplar focuses on the important case of addressing infection while avoiding the opportunity for increasing antimicrobial resistance, our protocol is agnostic with respect to the cellinstructive functionality and may, in principle, be substituted for any other library of materials. This method offers a flexible manufacturing platform suited to the production of medical devices truly tailorable to biological challenge and personalize suitable for translation into clinical practice. 


\section{Materials and Methods}

\section{Ink preparation}

All chemicals were purchased from Sigma-Aldrich and used as received. Tricyclo[5.2.1.02,6]decanedimethanol diacrylate (TCDMDA) and Ethylene glycol dicyclopentenyl ether acrylate (EGDPEA) were used as the base monomer in the preparation of all the ink formulations. The photoinitiators used were 2,2-Dimethoxy-2-phenylacetophenone 99\% (DMPA) (a type I photoinitiator for nitrogen atmosphere printing) and (2,4-Diethyl-9H-thioxanthen-9-one(DETX), 98\%)/(Ethyl 4(dimethylamino)benzoate(EDB), 99wt\%) (a type II photoinitiator system suitable for printing within an air atmosphere). $5 \mathrm{~mL}$ of each selected monomer was placed into capped vials (wrapped with aluminum foil) together with a photoinitiator $(0.5 \mathrm{wt} \%, 1 \mathrm{wt} \%, 2 \mathrm{wt} \%$ and $4 \mathrm{wt} \%)$ and stirred at 800 $\mathrm{rpm}$ at room temperature until the photoinitiator was fully dissolved. The mixture was degassed by purging with nitrogen for $15 \mathrm{~min}$ to remove dissolved oxygen. The inks were filtered through a 0.45 $\mu \mathrm{m}$ filter (Minisart, Sartorius Stedim Biotech) in a dark room to remove particulates which may block printer nozzles. In order to maximise printability, inks were sealed and stored at $4^{\circ} \mathrm{C}$ overnight to help release any bubbles generated during preparation ${ }^{[27]}$.

\section{Samples printing}

The printing was carried out using a Dimatix DMP-2830. $2 \mathrm{~mL}$ of ink was injected into a $10 \mathrm{pL}$ drop volume Dimatix cartridge containing 16 nozzles $(21 \mu \mathrm{m}$ nozzle size). The injection procedure was carried out in a dark room to prevent light-dependent inducing curing. The print cartridge was wrapped in foil to prevent ambient light curing during printing.

Curing was achieved using a UV unit $(365 \mathrm{~nm}$ and $600 \mathrm{~mW} / \mathrm{cm} 2)$ mounted directly on the printer allowing it to move with the printhead and induce real-time UV illumination and curing contemporaneously with deposition of material. 
All the samples with DMPA as a photoinitiator were printed in nitrogen where oxygen levels were controlled to $1 \pm 0.5 \%$. The inks with DETX/EDB as initiator were printed in air.

\section{Polymer mechanical and chemical properties}

Dynamic Mechanical Analysis (DMA) tests were carried out at room temperature using a Perkin Elmer DMA 8000 in tension mode. Specimens were printed following a rectangular pattern $(20 \mathrm{~mm}$ in length and $5 \mathrm{~mm}$ in width) with 100 layers. The test length was set to $10 \mathrm{~mm}$ and the width and thickness of each sample was measured prior to calculating its modulus. The test period was set to 10 min with 1 Hz extension frequency at room temperature. Infrared Spectroscopy (IR) with an ATR (Perkin Elmer UATR IR) sampling attachment was used to characterize the curability of the printed samples. The spectra for each set of samples were normalized with a peak at $1726 \mathrm{~cm}^{-1}$ representing the acrylate carboxyl group. The peak at $810 \mathrm{~cm}^{-1}$, which represents the carbon-hydrogen covalent bond on the $\mathrm{C}=\mathrm{C}$ pairing was used to compare the level of conversion of the printed samples.

\section{Mammalian Cell Cytotoxicity}

Following ISO 10993, Medical Device Tests guidance direct contact (cell attachment test) and indirect extractable testing (cytotoxicity test) was undertaken.

Cytotoxicity test: Samples were placed in a 96 well plate, and $1 \mathrm{~mL}$ of Industrial Methylated Spirit (IMS, 70\% v/v, Fisher Scientific, UK) was added and allowed to evaporate overnight in a microbiological safety cabinet at RT. Samples were washed three times for 5 min each with PBS. Cell culture medium was added $(200 \mu \mathrm{L})$ to each sample and kept in an incubator at $5 \% \mathrm{CO} 2$ in air, $37^{\circ} \mathrm{C}$. Conditioned medium was collected after 1, 3, 5 and 8 days, and replaced with $200 \mu \mathrm{L}$ of fresh medium. Cell culture media were prepared by adding $10 \%$ (v/v) of Foetal Bovine Serum (FBS, Sigma-Aldrich, UK), 2 mM L-glutamine (Sigma-Aldrich, UK) and $100 \mathrm{U} / \mathrm{mL}$ penicillin, $0.1 \mathrm{mg} / \mathrm{mL}$ streptomycin and $0.25 \mu \mathrm{g} / \mathrm{mL}$ amphotericin B (Sigma-Aldrich, UK). Immortalized NIH 3T3 mouse embryonic fibroblast 
cells (3T3s, passage 60) were seeded in a 96 well plate at a density of 5000 cells/well $(100 \mu \mathrm{L})$ and when they reached confluency, conditioned media were added and cells incubated for a further $24 \mathrm{~h}$ at $5 \% \mathrm{CO} 2$ in air at $37^{\circ} \mathrm{C}$. Cells cultured in fresh media were included as a control. The lactate dehydrogenase assay (LDH Assay Kit@, Thermo Scientific) and Presto Blue ${ }^{\circledR}$ assay (Invitrogen) were used to test the cytotoxicity of the conditioned media and cell viability, respectively (Supplementary Figure 3). The LDH assay was performed according to the manufacturer's protocol. Two controls were performed to obtain a spontaneous and a maximum LDH activity. The spontaneous activity was quantified using the medium collected from the controls, where cells were grown in fresh medium. To induce maximum activity, $10 \mu \mathrm{L}$ of Lysis Buffer (10X) were added to the cells grown in fresh medium for 30 min before assaying.

In brief, $50 \mu \mathrm{L}$ of each conditioned media sample were transferred to a 96 well plate and $50 \mu \mathrm{L}$ of the reaction mixture added to each sample, and the plate incubated at room temperature. After $30 \mathrm{~min}, 50$ $\mu \mathrm{L}$ of stop solution was added. The LDH activity was measured by reading the absorbance of the samples at $490 \mathrm{~nm}$ (subtracted from the $680 \mathrm{~nm}$ reading) using a spectrofluorometer (Tecan Infinite M200 microplate reader). The cytotoxicity of the extracts was calculated using the following equation:

$$
\% \text { Cytotoxicity }=\frac{\text { LDH activity of the sample }- \text { Spontaneous LDH activity }}{\text { Maximum LDH activity }- \text { Spontaneous LDH activity }} \times 100
$$

Mammalian cell metabolic activity: Presto blue ${ }^{\mathrm{TM}}$ was diluted 1:10 in cell culture medium and added to the cells. Following aspiration of the medium and washing in PBS for $45 \mathrm{~min}$ at $37^{\circ} \mathrm{C}, 5 \% \mathrm{CO} 2$ in air. The fluorescence intensity of the solution, which is proportional to cellular metabolic activity, was measured at 560 and $590 \mathrm{~nm}$, corresponding to the excitation and emission wavelengths, respectively, and the blank reading (medium without cells) subtracted from each value.

Mammalian cell attachment: Samples were placed in a 48 well plate, $1 \mathrm{~mL}$ of Industrial Methylated Spirit (IMS, 70\% v/v, Fisher Scientific, UK) was added and allowed to evaporate overnight in a microbiological safety cabinet at room temperature. Samples were washed three times for 5 min with 
PBS. To each sample, $400 \mu \mathrm{L}$ of cell culture medium was added for $24 \mathrm{~h}$. $3 \mathrm{~T} 3$ mouse fibroblast cells were seeded on the samples at a concentration of 40,000 cells/well in a total volume of $0.5 \mathrm{~mL}$. After $24 \mathrm{~h}$, the materials were transferred to a new plate to measure the metabolic activity of the cells attached to the scaffold using the Presto Blue assay. Fluorescence intensity was measured and the blank (medium without cells) was subtracted from each value. The test was performed after the cells had been in contact with the test material for $1,3,5$ and 7 days.

Live/Dead® cell viability assay: Calcein AM (2.5 $\mu \mathrm{M}$, representing live cells) and ethidium homodimer-1 (5 $\mu \mathrm{M}$, red, representing dead cells) were added to the samples and incubated for 30 min at $37^{\circ} \mathrm{C}$ at $5 \% \mathrm{CO}_{2}$, before imaging.

Statistical analyses were performed using Prism 6 (GraphPad Software, v6.01). Two-way ANOVA was performed on cell viability followed by Tukey post-hoc test $(n=3)$ and on LDH results followed by the Dunnett test $(n=5)$. A value of $p \leq 0.05$ was considered significant. For each condition, mean \pm standard deviation was reported.

Bacterial strains, growth conditions and intracellular ATP assay

P. aeruginosa PAO1 (Washington sub-line) and S. aureus SH1000 ${ }^{[39]}$ were routinely grown at $37^{\circ} \mathrm{C}$ in LB with shaking at $200 \mathrm{rpm}$ or on LB agar $(2 \% \mathrm{w} / \mathrm{v})$. Where required, plasmids for constitutively expressing fluorescent proteins GFP (pBK-miniTn7-egfp) and mCherry (pMMR) were introduced into the relevant host strain by conjugation or electroporation and maintained by supplementing the growth medium with the appropriate antibiotic.

For the quantification of ATP, P. aeruginosa and S. aureus cell culture samples were taken at early $(\mathrm{OD} 600 \mathrm{~nm}=0.25)$, mid $($ OD600nm $=0.5)$ or late $($ OD600nm $=0.8)$ exponential growth phase ATP levels were assayed using a BacTiter-GloTM Microbial Cell Viability Assay (Promega UK, Southampton, UK) according to manufacturer's instructions. 


\section{Bacterial Biofilm Formation}

Bacterial biofilm formation assays were conducted as follows. Briefly, UV-sterilized IJ3DP devices (cuboids, tablets or finger implants) with the developed formulations were incubated with bacteria at $37^{\circ} \mathrm{C}$ with $60 \mathrm{rpm}$ shaking for $72 \mathrm{~h}$ in RPMI-1640. Air-dried samples were examined using a Carl Zeiss LSM 700 laser scanning confocal microscope fitted with $405 \mathrm{~nm}, 488 \mathrm{~nm}$ and $555 \mathrm{~nm}$ excitation lasers and a 10x/NA 0.3 objective. Images were acquired using ZEN 2009 imaging software (Carl Zeiss). Bacterial surface coverage was quantified using Image J 1.44 software (National Institutes of Health, USA) and Comstat $\mathrm{B}^{[40]}$.

\section{Mouse foreign body infection model}

All animal experiments were approved following local ethical review at the University of Nottingham and performed under Home Office licence 30/3082. Female BALB/c mice, 19-22g (Charles River; 3 mice per infected implant and 2 mice per uninfected implant control) were housed in individually vented cages under a $12 \mathrm{~h}$ light cycle, with food and water ad libitum. P. aeruginosa (strain PAO1-L CTX:tac-lux) was grown overnight in $\mathrm{LB}$ broth at $37^{\circ} \mathrm{C}$, diluted $1: 100$ in $\mathrm{LB}$ and grown at $37^{\circ} \mathrm{C}$ to mid-log phase (OD600). The cultures were washed in PBS+10\% v/v glycerol and aliquots stored at $80^{\circ} \mathrm{C}$. When required, aliquots were removed, serially diluted and cultured on LB agar plates and the number of colony forming units (CFUs) determined. One hour before device implantation via a Trocar needle, Carprofen $(2.5 \mathrm{mg} / \mathrm{kg})$ was administered by subcutaneous injection to reduce pain and inflammation. Animals were anaesthetised with $2 \%$ isoflurane, their flanks shaved and the skin cleaned with Hydrex surgical scrub. A small incision was made and the catheter implanted via a 9g trocar needle and closed with Gluture skin glue (Abbott Laboratories). Mice were allowed to recover for 4 days. Under anaesthesia, $10^{5}$ bioluminescent $P$. aeruginosa cells in $20 \mu \mathrm{PBS}$ were injected into the IJ3DP devices implanted in the mice. The progress of bacterial infection was imaged as bioluminescence using an IVIS ${ }^{\mathrm{TM}}$ Spectrum (Perkin Elmer). The infected animals were tracked daily 
for 5 days via whole animal imaging for the presence of metabolically active bacteria at the infection site. After sacrificing the mice, the IJ3DP devices and the surrounding tissues were removed and reimaged ex vivo using an IVIS ${ }^{\mathrm{TM}}$ Spectrum to quantify bacterial bioluminescence. In addition, the implants were fixed with $10 \%$ formal saline and subjected to immunohistochemical analysis and confocal microscopy using antibodies raised against $P$. aeruginosa cells (Invitrogen) and detected using a secondary goat anti-mouse fluorescent conjugate (quantum dot 705; Thermofisher). Total host cell and bacterial membrane biomass on the implants was stained using the fluorescent cell membrane probe, FM1-43 (Thermofisher). After staining implants were imaged using by confocal fluorescence microscopy (Zeiss LSM700). 


\section{References and Notes}

[1] Culmone, C., Smit, G., Breedveld, P., Additive Manufacturing of Medical Instruments: A state of the art review, Additive Manufacturing, 27, 461-473. 2019

[2] Kang, H. W., Lee, S. J., Ko, I. K., Kengla, C., Yoo, J. J., Atala, A., A 3D Bioprinting System to Produce Human-scale Tissue Constructs with Structural Integrity, Nature Biotechnology, 34(3), 312-319. 2016

[3] Giannopoulos, A. A., Mitsouras, D., Yoo, S. J., Liu, P. P., Chatzizisis, Y. S., Rybicki, F. J., Applications of 3D Printing in Cardiovascular Diseases, Nature Reviews Cardiology, 13(12), 701-718. 2016,

[4] Green, J. J., \& Elisseeff, J. H., Mimicking Biological Functionality with Polymers for Biomedical Applications, Nature, 540(7633), 386-394. 2016

[5] Kim, S. H., Moon, J. H., Kim, J. H., Jeong, S. M., Lee, S. H. Flexible, Stretchable and Implantable PDMS encapsulated Cable for Implantable Medical Device, Biomedical Engineering Letters, I(3), 199-203. 2011

[6] Mata, A., Fleischman, A. J., Roy, S. Characterization of Polydimethylsiloxane (PDMS) properties for Biomedical Micro/nanosystem, Biomedical Microdevices, 7(4), 281-293. 2005

[7] Donlan, R. M., Biofilms and Device-associated Infections, Emerging Infectious Diseases, 7(2), 277. 2001

[8] Salvati, E. A., Robinson, R. P., Zeno, S. M., Koslin, B. L., Brause, B. D., Wilson Jr, P. D., Infection Rates after 3175 Total Hip and Total Knee Replacements Performed with and without a Horizontal Unidirectional Filtered Air-flow System, Journal of Bone and Join Surgery, 64(4), 525-535. 1982

[9] Inman, R. D., Gallegos, K. V., Brause, B. D., Redecha, P. B., Christian, C. L., Clincal and Microbial Features of Prosthetic Joint Infection, The American Journal of Medicine, 77(1), 47-53. 1984

[10] Brouqui, P., Rousseau, M. C., Stein, A., Drancourt, M., Raoult, D., Treatment of Pseudomonas aeruginosa-infected orthopedic prostheses with ceftazidime-ciprofloxacin antibiotic combination, Antimicrobial Agents and Chemotherapy, 39(11), 2423-2425. 1995

[11] García-Alvarez R, Izquierdo-Barba I, Vallet-Regí M., 3D scaffold with effective multidrug sequential release against bacteria biofilm, Acta Biomaterialia, 49: 113-126. 2017

[12] Aldrich A, Kuss M A, Duan B, Kielian T., 3D bioprinted scaffolds containing viable macrophages and antibiotics promote clearance of Staphylococcus aureus craniotomy-associated biofilm infection, ACS Applied Materials \& Interfaces. 11, 12298-12307. 2019

[13] Weisman J A, Ballard D H, Jammalamadaka U, Tappa K., Sumerel J., D’Agostino HB. Mills DK., Woodard PK., 3D printed antibioticand chemotherapeutic eluting catheters for potential use in interventional radiology: in vitro proof of concept study, Academic Radiology, 26(2): 270-274. 2019,

[14] García-Alvarez R, Izquierdo-Barba I, Vallet-Regí M., 3D scaffold with effective multidrug sequential release against bacteria biofilm, Acta Biomaterialia, 49: 113-126. 2017

[15] Amin Yavari S, Loozen L, Paganelli F L, Bakhshandeh S., Lietaert K., Groot J A, Fluit A C, Boel C H E, Alblas J, Vogely H C, Weinans H, Zadpoor A A., Antibacterial behaviorof additively manufactured porous titanium with nanotubular surfaces releasing silver ions, ACS Applied Materials \& Interfaces, 8(27): 17080-17089. 2016

[16] Lee D K., Drug-eluting Stent in Malignant Biliary Obstruction, Journal of Hepato-biliary-pancreatic Surgery, 16(5): 628-632. 2009

[17] Zhou Z, Yao Q, Li L, Zhang X, Wei B, Yuan L, Wang L, Antimicrobial Activity of 3D-Printed Poly(ع-Caprolactone) (PCL) Composite Scaffolds Presenting Vancomycin-Loaded Polylactic Acid-Glycolic Acid (PLGA) Microspheres, Medical Science Monitor: International Medical Journal of Experimental and Clinical Research, 24: 6934. 2018

[18] Inzana J A, Trombetta R P, Schwarz E M, Kate S L, Award H A, 3D Printed Bioceramics for Dual Antibiotic Delivery to Treat Implant Associated Bone Infection, European Cells \& Materials, 30: 232. 2015

[19] O’Neill J., Tackling Drug-resistant Infections globally: Final Report and Recommendations. Review on Antimicrobial Resistance. 2016

[20] Hook, A. L., Chang, C. Y., Yang, J., Atkinson, S., Langer, R., Anderson, D. G. \& Alexander, M. R. Discovery of Novel Materials with Broad Resistance to Bacterial Attachment Using Combinatorial Polymer Microarrays, Advanced Materials, 25(18), 2542-2547. 2013

[21] Hook, A. L., Chang, C. Y., Yang, J., Luckett, J., Cockayne, A., Atkinson, S., Mei Y, Bayston R, Irvine D J, Langer R, Anderson, D. G., William P, Davies M C, Alexander M R, Combinatorial Discovery of Polymers Resistant to Bacterial Attachment, Nature Biotechnology, 30(9), 868-875. 2012,

[22] Hook, A. L., Anderson, D. G., Langer, R., Williams, P., Davies, M. C., \& Alexander, M. R. High Throughput Methods Applied in Biomaterial Development and Discovery, Biomaterials, 31(2), 187-198. 2010 
[23] Dundas A.A., Sanni O., Dubern J., Dimitrakis G., Hook A.L., Irvine D.J., Williams P., Alexander M.R., Validating a Predictive Structure-Property Relationship by Discovery of Novel Polymeris which Reduce Bacterial Biofilm Formation, Advanced Materials, 31(49), 1903513, 2019

[24] Gibson I., Rosen D.W., Stucker B., Additive Manufacturing Technologies, New York, Springer, 2014

[25] He Y, Wildman R D, Tuck C J, Christie S D R, Edmondson S, An Investigation of the Behavior of Solvent based Polycaprolactone Ink for Material Jetting, Scientific reports, 6: 20852. 2016

[26] Begines, B., Begines, B., Hook, A. L., Hook, A. L., Alexander, M. R., Alexander, M. R. \& Wildman, R. D., Development, Printability and Post-curing Studies of Formulations of Materials Resistant to Microbial Attachment for Use in Inkjet based 3D Printing, Rapid Prototyping Journal, 22(5), 835-841. 2016

[27] He, Y, Foralosso R, Trindade G F, Ilchev A, Ruiz-Cantu L, Clark E A, Khaled S, Hague R J M, Tuck C J, Rose F R A J, Mantovani G, Irvine D J, Robert C J, Wildman R D, A Reactive Prodrug Ink Formulation Strategy for Inkjet 3D Printing of Controlled Release Dosage Forms and Implant, Advanced Therapeutics, doi: 1900187, 1-6, 2020,

[28] Chen X, Ashcroft I A, Tuck C J, He Y, Hague R J M, Wildman R D, An Investigation into The Depth and Time Dependent Behavior of UV Cured 3D Inkjet Printed Objects, Journal of Materials Research, 32(8): 1407-1420. 2017

[29] Wang X, Qin X H, Hu C, Terzopoulou A, Chen X, Huang T, Maniura-Weber K, Pane S, Nelson B J, 3D Printed Enzymatically Biodegradable Soft Helical Microswimmers, Advanced Functional Materials, 28(45): 1804107. 2018

[30] Wang Y, Li Y, Yu X, Long Q, Zhang T, Synthesis of a Photocurable Acrylated Poly (ethylene glycol)-co-poly (xylitol sebacate) Copolymers Hydrogel 3D printing Ink for Tissue Engineering, RSC Advances, 9(32): 18394-18405. 2019

[31] Butz, K. D., Merrell, G., \& Nauman, E. A., A three-dimensional finite element analysis of finger joint stresses in the MCP joint while performing common tasks, Hand, 7(3), 341-345. 2012

[32] Morgan, E. F., Bayraktar, H. H., \& Keaveny, T. M. Trabecular bone modulus-density relationships depend on anatomic site.Journal of Biomechanics, Journal of Biomechanics, 36(7), 897-904. 2003

[33] Bayraktar, H. H., \& Keaveny, T. M., Mechanisms of uniformity of yield strains for trabecular bone, Journal of Biomechanics, 37(11), 1671-1678. 2004

[34] Biological evaluation of medical devices -- Part 1: Evaluation and testing within a risk management process, ISO 10993-1: 2009

[35] Stryker, Silicone PIP, MCP \& MCP-X (PreFlex) Finger Joint Arthroplasty, http://az621074.vo.msecnd.net/sykmobile-content-cdn/global-content-system/SYKGCSDOC-2-

43450/RuWR3YudnAbz4MXCiXG2d6fnbqEkZA/SMCP_ST_1.pdf, 2016

[36] Brouqui, P., Rousseau, M. C., Stein, A., Drancourt, M., Raoult, D., Treatment of Pseudomonas aeruginosa-infected orthopedic prostheses with ceftazidime-ciprofloxacin antibiotic combination, Antimicrobial Agents and Chemotherapy, 39(11), 2423-2425. 1995

[37] Vallieres, C., Hook, A. L., He, Y., Crucitti, V. C., Figueredo, G., Davies, C. R., Burroughs L., Winkler D.A., Wildman R.D., Irvine D.J., Alexander, M. R., Avery S.V., Discovery of (meth) acrylate polymers that resist colonization by fungi associated with pathogenesis and biodeterioration. Science Advances, 6(23), eaba6574. 2020

[38] He, Y., Zhang, F., Saleh, E., Vaithilingam, J., Aboulkhair, N., Begines, B Tuck C.J., Hague R.J.M., Ashcroft I.A., Wildman, R. D. A tripropylene glycol diacrylate-based polymeric support ink for material jetting. Additive Manufacturing, 16, 153-161, 2017

[39] Horsburgh, B., Aish, J. L., White, I. J., Shaw, L., Lthgow, J. K. \& Foster, S. J., SigmaB modulates virulence determinant expression and stress resistance: characterization of a functional rsbU strain derived from Staphylococcus aureus, Journal of Bacteriology, 184(19), 5457-5467. 2002

[40] Heydorn, A., Nielsen, A. T., Hentzer, M., Sternberg, C., Givskov, M., Ersbøll, B. K. \& Molin, S., Quantification of biofilm structures by the novel computer program COMSTAT, Microbiology, 146(10), 2395-2407. 2000 


\section{Acknowledgments}

YH, RW, CT, RH, and BB were funded by Engineering and Physical Sciences Research Council grants EP/I033335/2, EP/N024818/1 and EP/P031684/1, EP and FR by EP/L015072/1 and MA, PW, J-FD

by the Wellcome Trust Senior Investigator Joint Awards to 103882/Z/14/Z and 103884/Z/14/Z. Funding for open access charge was provided by UK Research and Innovation.

The manuscript was written with contributions of all authors. The majority of the experimental work was carried out by YH. Support for 3D printing was provided by BB, RW, CT and RH. JL conducted in vivo mouse experiments and J-FD and $\mathrm{AH}$ conducted the in vitro bacterial assays overseen by $\mathrm{PW}$. Cytotoxicity experiments were conducted by EP under the supervision of FR. Chemical characterisation and materials understanding was overseen by DI. The work was conceived and organised by RW, MA and PW. 
bioRxiv preprint doi: https://doi.org/10.1101/2020.06.30.180596; this version posted July 2, 2020. The copyright holder for this preprint (which was not certified by peer review) is the author/funder, who has granted bioRxiv a license to display the preprint in perpetuity. It is made available under aCC-BY-NC-ND 4.0 International license.

\section{Figures and Tables}

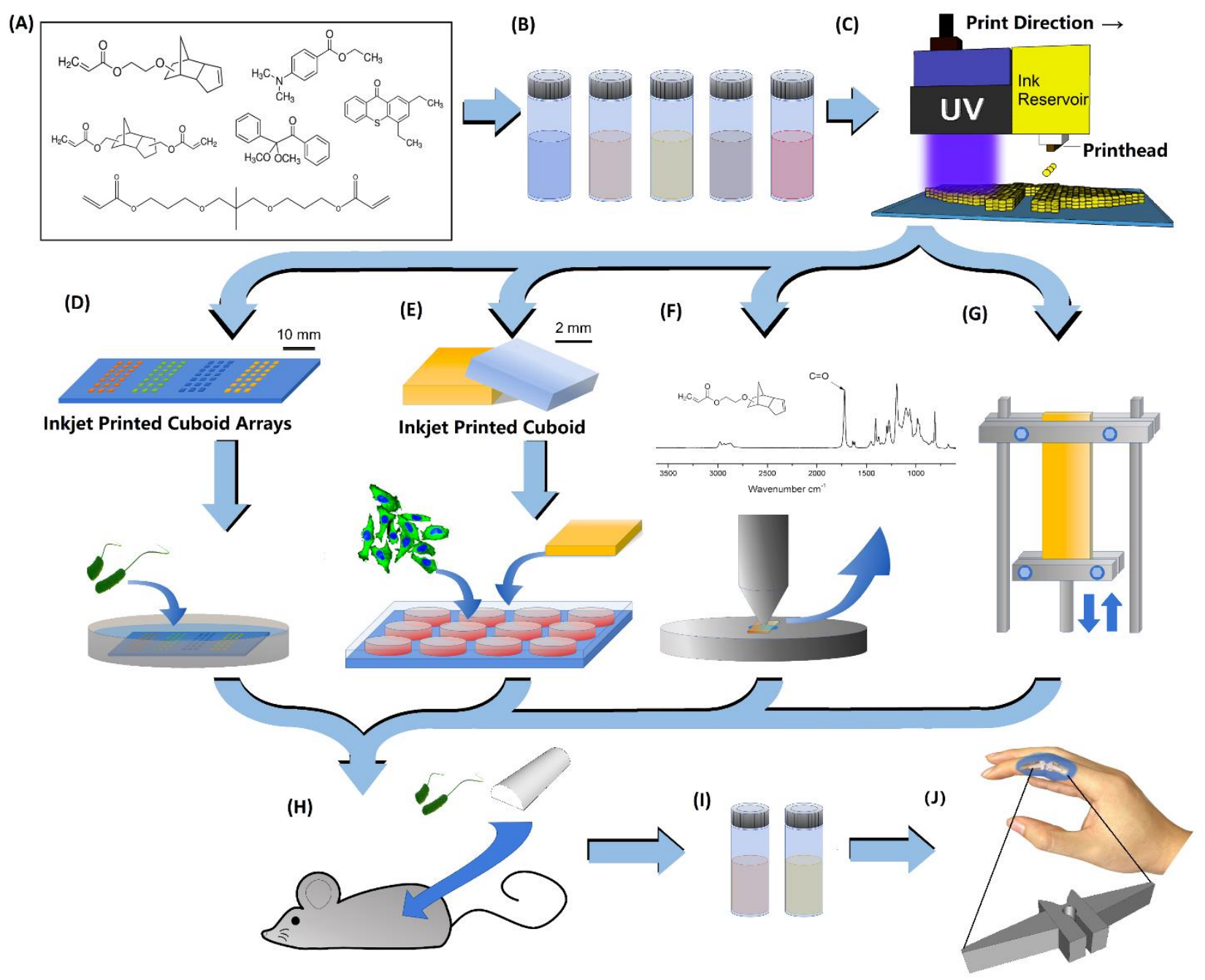

Fig. 1: Schematic for developing optimized formulations for IJ3DP. A-B) Selected monomer candidates for the formulation development and optimization. C) A Fujifilm Dimatix DMP-2830 3D printer was used to print samples. The system in this case was equipped with a cartridge ejecting $10 \mathrm{pL}$ drop volumes, utilising up to 16 nozzles. D) On slide arrays of cuboids were created by IJ3DP for preliminary microbiology biofilm assays using P. aeruginosa. E) Cytotoxicity and cell attachment biocompatibility tests on the printed samples were carried out using mouse embryonic fibroblast $3 T 3$ fibroblasts to assess biocompatibility of the printed device; F) Attenuation Total Reflectance Infrared Spectroscopy (ATR-IR) was used to quantify the levels of residual acrylate in the specimens made from different ink formulations; $\boldsymbol{G})$ Mechanical tests were performed by Dynamic Mechanical Analysis (DMA) in tension mode at room temperature; $\boldsymbol{H})$ Formulations resulting in acceptable properties were tested in vivo to ensure the cell instructive retained in a more complex environment; I-J) The finalized ink formulations were used to print concept devices. 
(A)

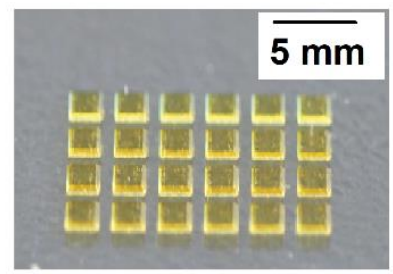

\section{Printed Cuboid Array}

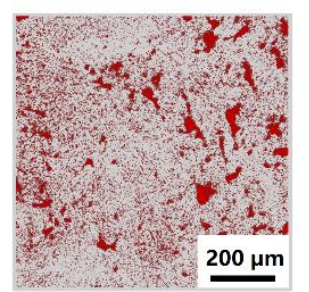

Bacterial Assessment

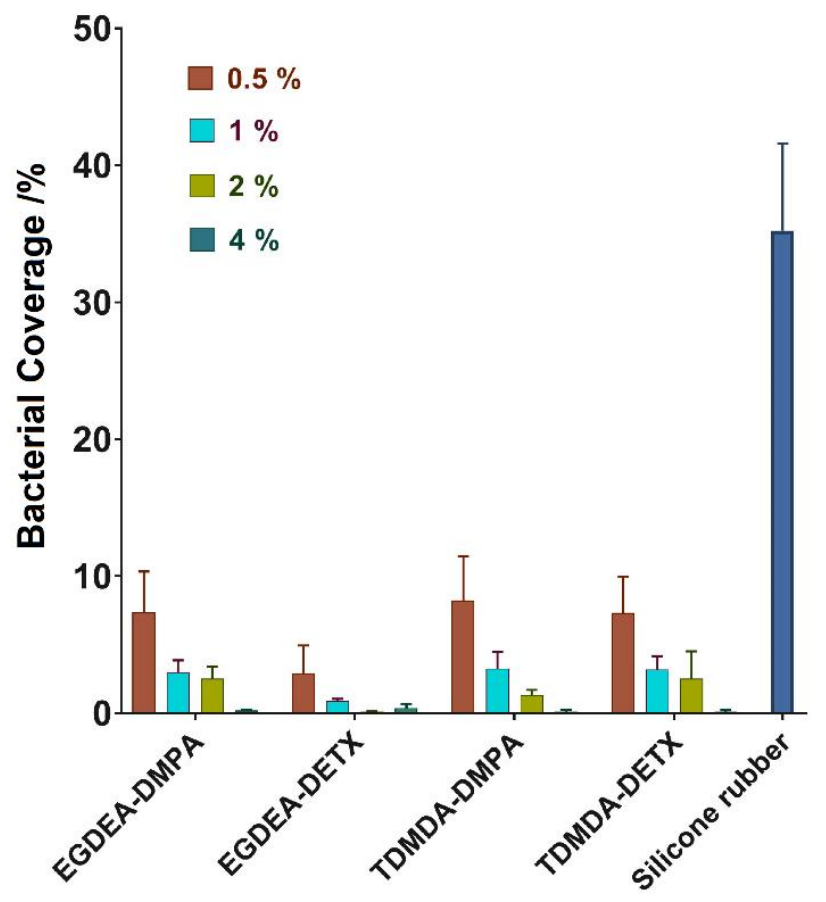

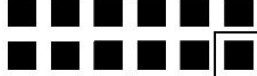

(B)
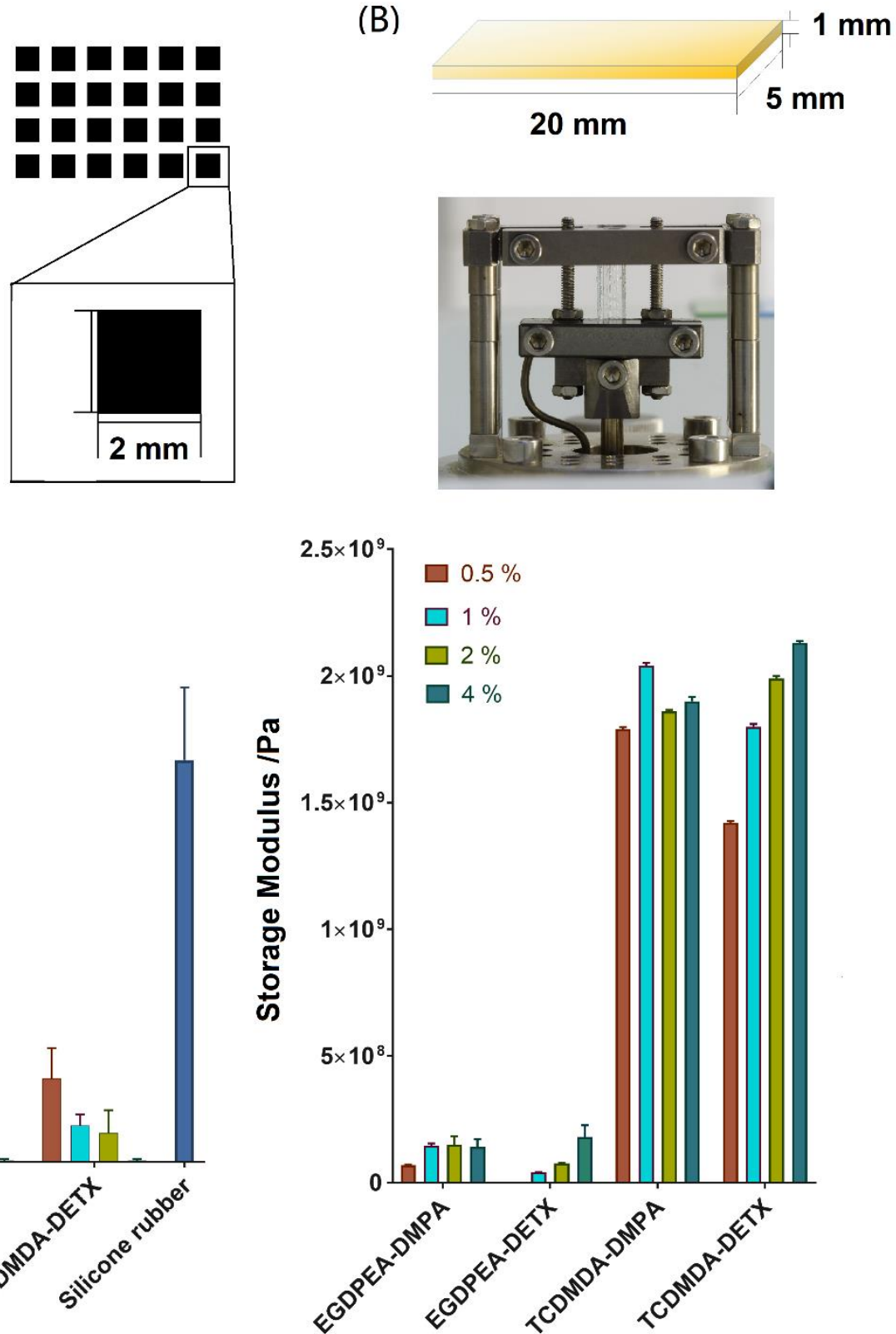

Fig. 2: Comparison of the mechanical and bacterial biofilm inhibition performance between IJ3DP printed specimens using selected ink formulations: A) An array of 24 cuboids ( $2 \mathrm{~mm} \times 2 \mathrm{~mm} \times 0.1 \mathrm{~mm} ; \mathrm{w} \times \mathrm{l} \times \mathrm{h})$ was printed onto polystyrene slides and bacterial biofilm formation compared with a silicone control; the samples were imaged after incubation with $\mathrm{P}$. aeruginosa using confocal microscopy and biofilm surface coverage was assessed over $640 x$ $640 \mu \mathrm{m}$ and presented as surface coverage (\%) over the whole assessment window (Mean \pm Standard Deviation, $n=$ $24) ; \boldsymbol{B})$ The storage modulus of specimens made from all the formulations were measured by dynamic mechanical analysis using strip samples printed ( $5 \mathrm{~mm} \times 20 \mathrm{~mm} \times 1 \mathrm{~mm}(w \times l \times h))($ Mean \pm Standard Deviation, $n=5)$. 
bioRxiv preprint doi: https://doi.org/10.1101/2020.06.30.180596; this version posted July 2, 2020. The copyright holder for this preprint (which was not certified by peer review) is the author/funder, who has granted bioRxiv a license to display the preprint in perpetuity. It is made available under aCC-BY-NC-ND 4.0 International license.

(A)

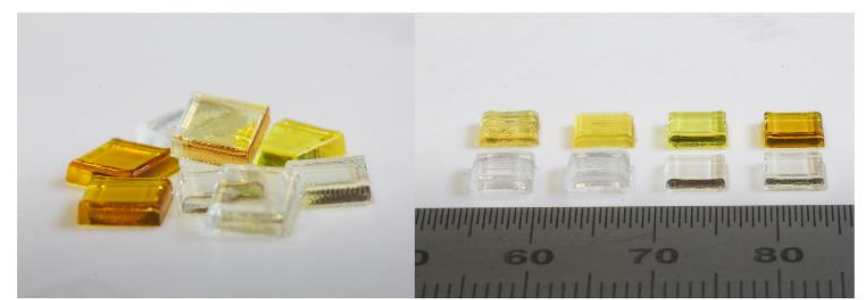

(D)

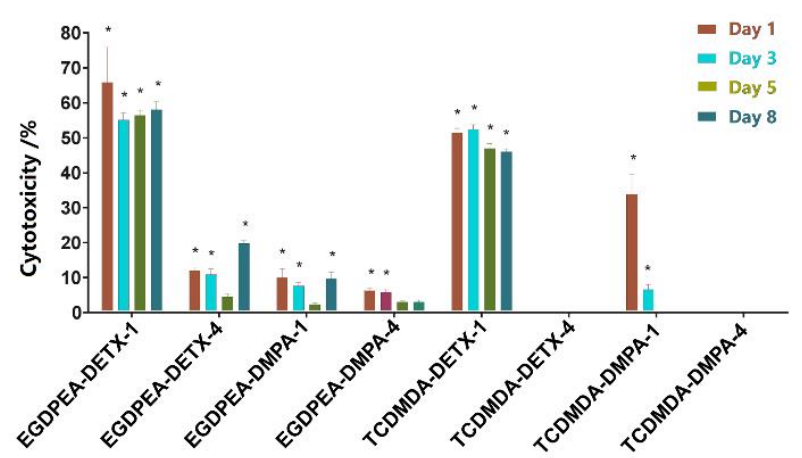

(B)
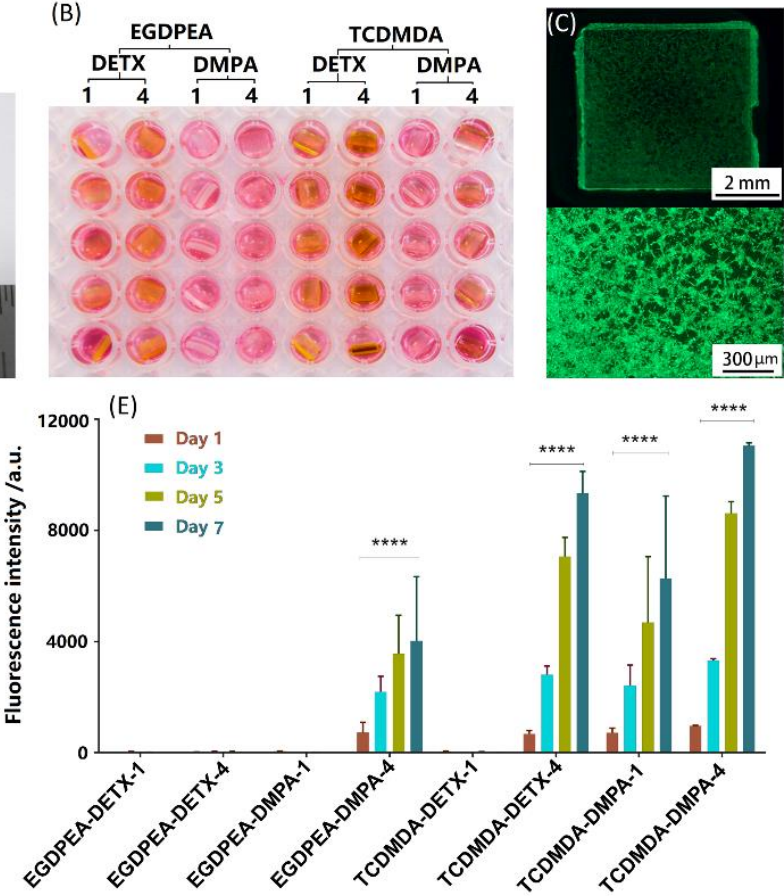

Fig. 3: Mammalian $3 T 3$ cell cytotoxicity and attachment tests on printed devices. A) Cuboid tablets were printed with the ink formulations in Table S1. B) Samples were immersed in culture medium over time (1, 3, 5, and 8 days), and samples transferred to plates containing adherent $3 T 3$ cells. C) An example of the Live/Dead® cell viability assay, which in this case was performed on a poly-TCDMDA-DMPA-4 sample illustrating viable cells and proliferation. D) Comparison of cytotoxicity (\%) for the printed cuboid tablets on different days performed using the LDH assay. Mean \pm Standard Deviation with $n=5$. E) Fluorescence intensity of 373 cells seeded on the samples in different formulations measured using the Presto Blue assay. The cells adhered and proliferated on 4 formulations (EGDPEA-DMPA-4, TCDMDA-DETX-4, TCDMDA-DMPA-1, and TCDMDA-DMPA-4); cells cultured on TCDMDA-DMPA-4 demonstrated the highest cell metabolic activities at day 7. Mean \pm Standard Deviation, $n=5\left({ }^{*} p \leq 0.05\right)$. 
(A)

DMPA

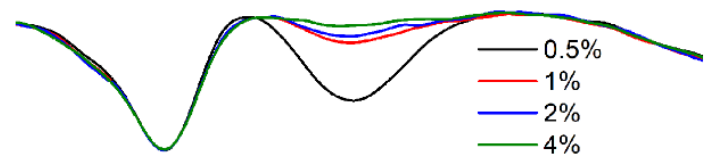

DETX

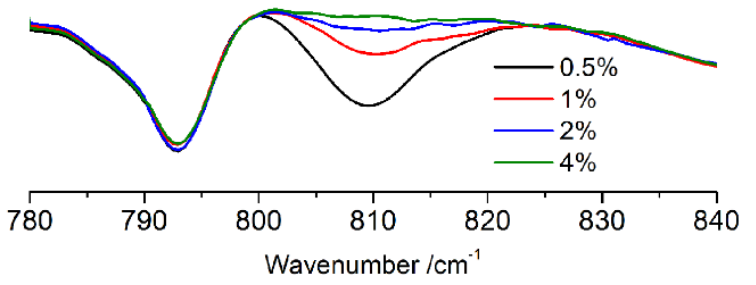

(B)

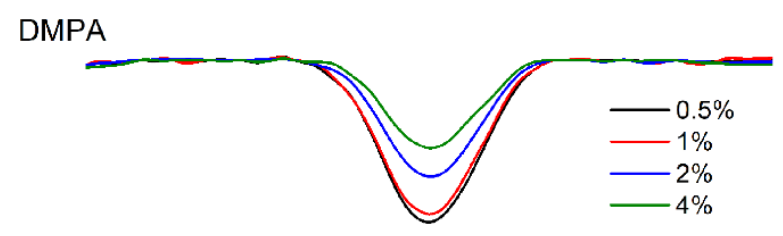

DETX
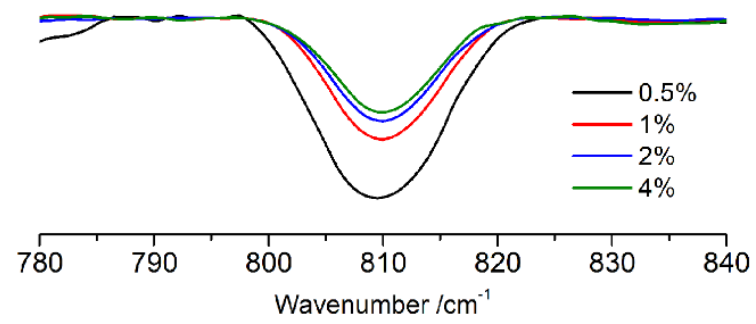

(C)

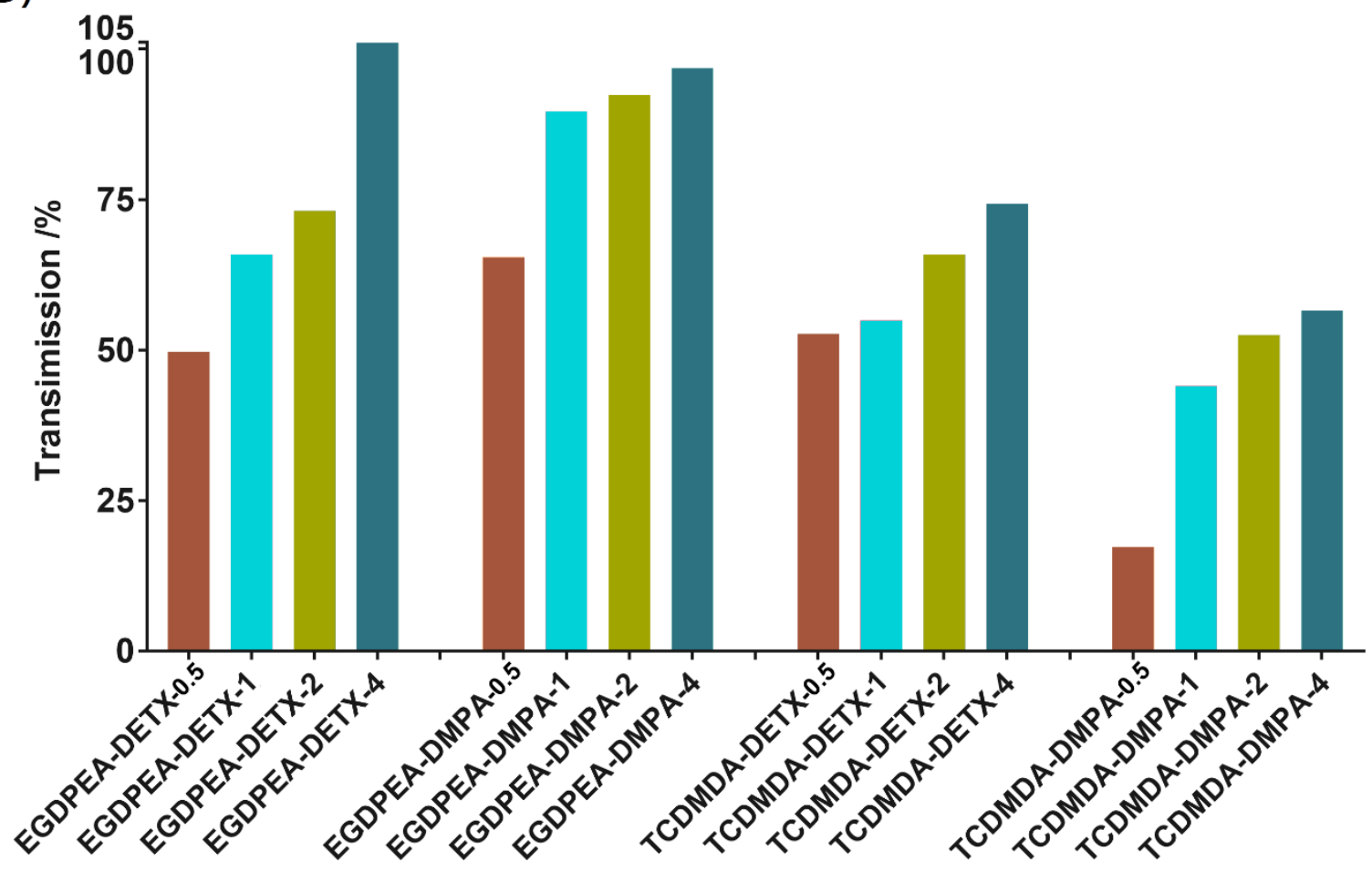

Fig 4: analysis highlighting the trends in residual alkene groups representing the residual monomer and inversely proportional to the level of conversion: The $810 \mathrm{~cm}^{-1}$ absorption assigned to the $C-H$ out-of-plane bending vibration of the alkene group displayed normalised to the background intensity. The materials interrogated were A) polyEGDPEA, and B) poly-TCDMDA; C) Plot of the transmission peak height at $810 \mathrm{~cm}^{-1}$. 

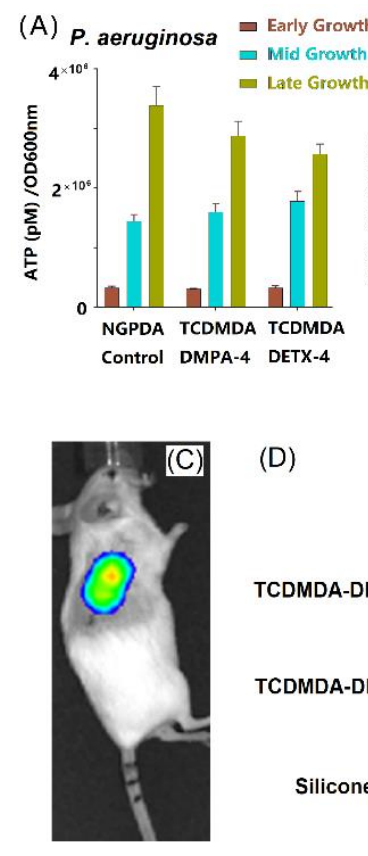

(D)
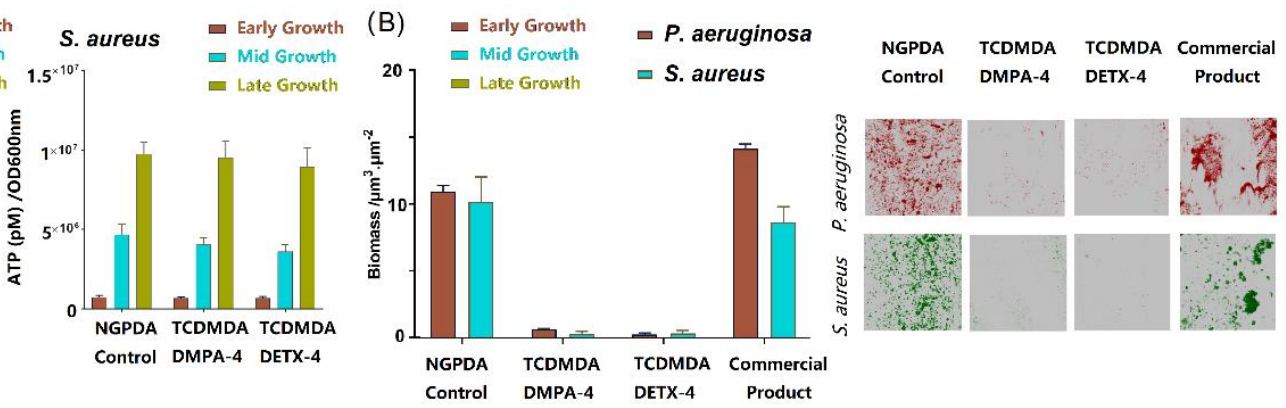

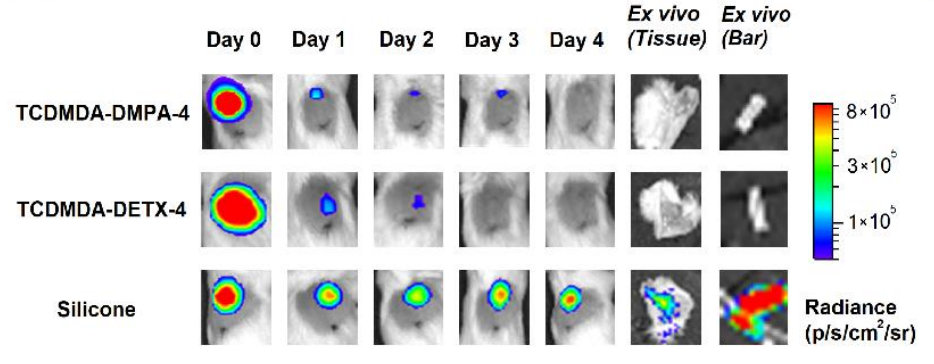

(E)

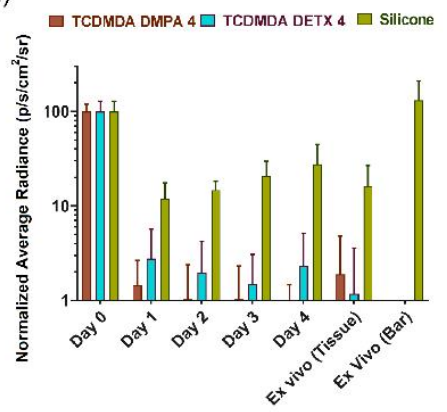

Fig.5 Assessment of bacterial viability and biofilm formation in vitro and infection in vivo in a mouse foreign body infection model. A) Bacterial cell viability on printed specimens, RPMI-1460 medium containing the printed sample was inoculated with either P. aeruginosa (left) or S. aureus (right) cells. Intracellular ATP levels were quantified at early $(O D 600 \mathrm{~nm}=0.25)$, mid $(O D 600 \mathrm{~nm}=0.5)$ and late $(O D 600 \mathrm{~nm}=0.8)$ exponential phase using a BacTiter-Glo microbial cell viability assay, NGPDA with 4 wt \% of DMPA as initiator was used as a control. Data show mean \pm standard deviation, $n=3$; B) Bacterial biofilm formation on printed specimens in vitro: the biofilm biomass of $\mathrm{P}$. aeruginosa and $\mathrm{S}$. aureus was measured after $72 \mathrm{~h}$ incubation. Error bars equal \pm one standard deviation unit, $n=3$. Fluorescent micrographs of mCherry-labelled $\mathrm{P}$. aeruginosa (red) and GFP-labelled S. aureus (green) growing on each surface (right). mean \pm standard deviation, $n=3$. Each image is $610 \times 610 \mu \mathrm{m} 2$. C) IJ3DP optimized formulations (TCDMDA-DMPA-4 and TCDMDA-DETX-4) and biomedical grade silicone sections (as controls) were implanted subcutaneously in mice. After inoculation, light emission from bioluminescent $\mathrm{P}$. aeruginosa at the infection site was measured on the day of inoculation. D) Representative bioluminescence outputs overlaid with bright field images of implanted mice infected with $\mathrm{P}$. aeruginosa and captured on days 0 to 4 . The implanted devices and surrounding tissues were also removed on day 4 from each animal and the device-associated bioluminescence quantified ex vivo. $\boldsymbol{E}$ ) Bioluminescence was normalised to the output on day 0 showing that the IJ3DP devices were colonized with considerably lower levels of metabolically active bacteria compared with the silicone control. 
bioRxiv preprint doi: https://doi.org/10.1101/2020.06.30.180596; this version posted July 2, 2020. The copyright holder for this preprint (which was not certified by peer review) is the author/funder, who has granted bioRxiv a license to display the preprint in perpetuity. It is made available under aCC-BY-NC-ND 4.0 International license.

(A)

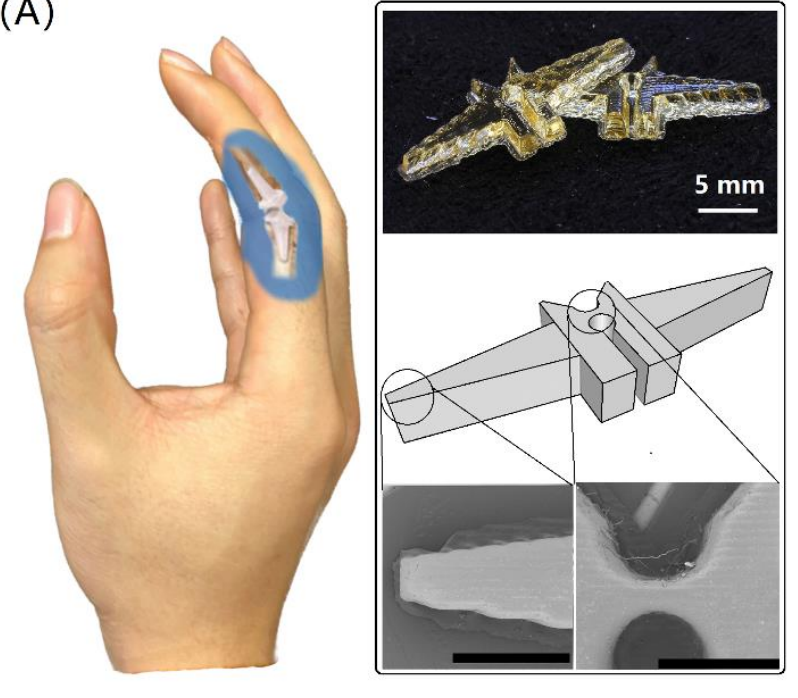

(B)

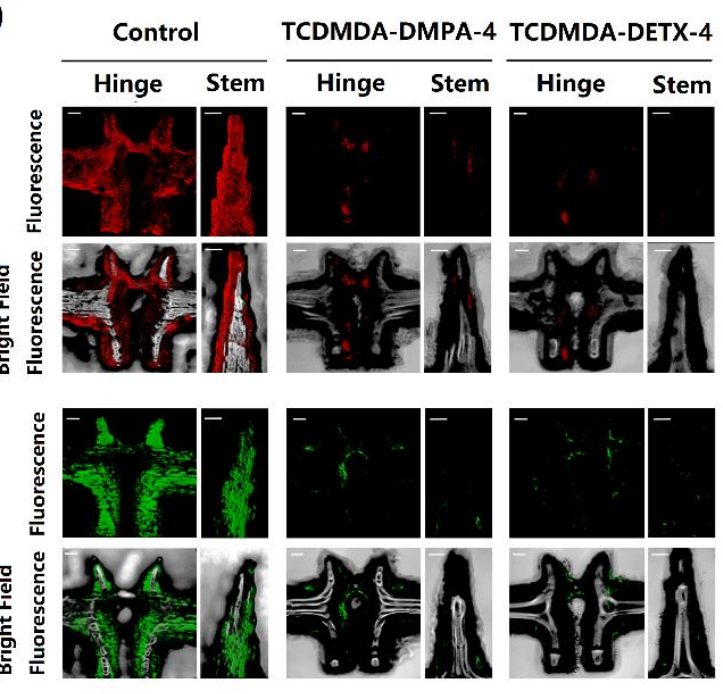

(C)
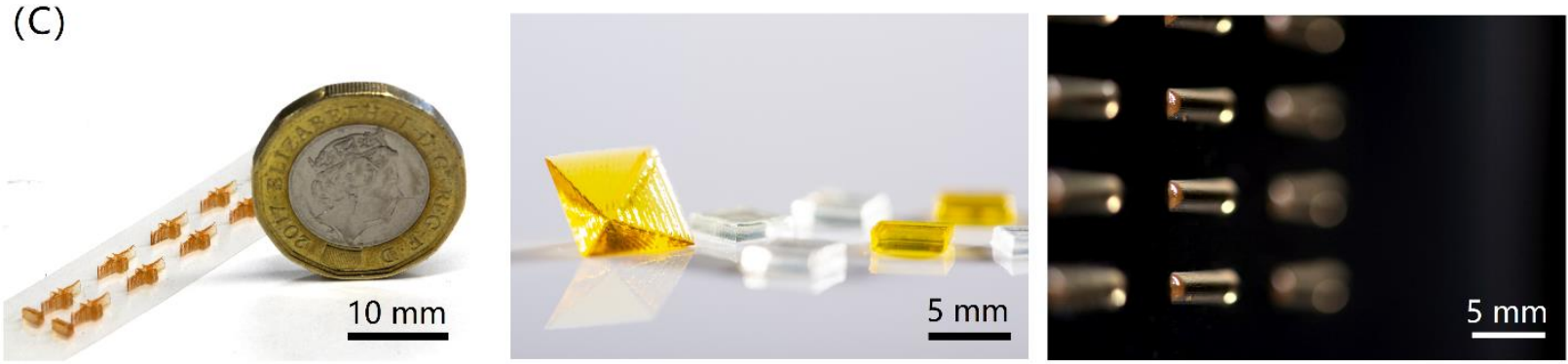

Fig. 6: IJ3DP printed finger prosthesis and other demonstrators using the developed ink formulations: A) IJ3DP printed finger prosthesis with the developed ink formulations, composed of a central hinge region between two stems, scale bars in the SEM images are $2 \mathrm{~mm} ; \boldsymbol{B})$ Fluorescence and overlaid fluorescence-brightfield confocal microscopy $3 D$ images showing in vitro biofilm formation imaged using $m$ Cherry-labelled $\mathrm{P}$. aeruginosa (red) and GFP-labelled S. aureus (green) on IJ3DP finger implants with the developed ink formulations. Scale bars represent $200 \mu \mathrm{m}$; C) specimens of different geometries printed with developed ink using Dimatix printing platform. 


\section{Supplementary Materials for}

\section{Inkjet based 3D Printing of bespoke medical devices that resist bacterial biofilm formation}

Yinfeng He ${ }^{1}+$, Belen Begines ${ }^{2}+$, Jeni Luckett ${ }^{4}$, Jean-Frédéric Dubern ${ }^{4}$, Andrew L. Hook ${ }^{3}$, Elisabetta Prina ${ }^{3}$, Felicity R.A.J. Rose ${ }^{3}$, Christopher J. Tuck ${ }^{1}$, Richard J.M. Hague ${ }^{1}$, Derek J. Irvine $^{1}$, Paul Williams ${ }^{4}$, Morgan R. Alexander ${ }^{3 *}$ and Ricky D. Wildman ${ }^{*}$

Table S1: Monomers that have shown resistance to bacterial biofilm resistance after polymerization were selected from polymer library and tested using our Dimatix DMP 2830 printing platform to assess if they are printable and curable in IJ3DP process. Printability is assumed within the range $1<\mathrm{Z}<10^{[27]}$ and then an assessment of whether reliable and consistent printing was possible was made by manual observation of the droplet formation and deposition. Curing was assessed by observing whether a 3D printed material was self-supporting.

\begin{tabular}{|c|c|c|c|c|c|c|}
\hline Monomer & $\begin{array}{l}\text { Viscosity at } \\
25^{\circ} \mathrm{C}(\mathrm{cp})\end{array}$ & $\begin{array}{l}\text { Surface } \\
\text { tension at } \\
25^{\circ} \mathrm{C}(\mathrm{mN} / \mathrm{m})\end{array}$ & $\begin{array}{l}\text { Density at } \\
25^{\circ} \mathrm{C} \\
(\mathrm{g} / \mathrm{mL})\end{array}$ & $\mathrm{Z}$ value & Printability & $\begin{array}{l}\text { Cured } \\
\text { following } \\
\text { IJ3DP } \\
\text { (in air) }\end{array}$ \\
\hline $\begin{array}{l}\text { Ethylene glycol dicyclopentenenyl } \\
\text { Ether acrylate }\end{array}$ & $17.2^{[30]}$ & $36.5^{[30]}$ & $1.085^{*}$ & 1.68 & $\sqrt{ }$ & $\sqrt{ }$ \\
\hline Bisphenol A glycerolate diacrylate & $>2000^{*}$ & $\mathrm{~N} / \mathrm{A}$ & $1.18 *$ & N/A & $x$ & $\mathrm{~N} / \mathrm{A}$ \\
\hline Tert-butylcyclohexylacrylate & 8.8 & 44.61 & $1.108 *$ & 3.66 & $\sqrt{ }$ & $\times$ \\
\hline Cyclohexyl methacrylate & 2.3 & 30.5 & $0.964 *$ & 10.80 & $\sqrt{ }$ & $\times$ \\
\hline Tert-butyl acrylate & 0.9 & 25.1 & $0.883 *$ & 23.97 & Not stable & $\times$ \\
\hline $\begin{array}{l}\text { Tricyclo[5.2.1.02,6]decanedimethanol } \\
\text { diacrylate }\end{array}$ & $118.3^{[29]}$ & $35.8^{[30]}$ & $1.1 *$ & 0.24 & $\sqrt{ }$ & $\sqrt{ }$ \\
\hline $\begin{array}{l}\text { Neopentyl glycol diacrylate (positive } \\
\text { control) }\end{array}$ & 18.1 & 30.2 & $1.003 *$ & 1.39 & $\sqrt{ }$ & $\sqrt{ }$ \\
\hline Ethyl methacrylate & 0.7 & 36.2 & $0.913 *$ & 37.63 & Not stable & $\times$ \\
\hline Ethylhexyl acrylate & $1.5^{[30]}$ & $25.9^{[30]}$ & $0.885 *$ & 14.62 & Not stable & $\times$ \\
\hline
\end{tabular}

*data from Sigma-Aldrich 
bioRxiv preprint doi: https://doi.org/10.1101/2020.06.30.180596; this version posted July 2, 2020. The copyright holder for this preprint (which was not certified by peer review) is the author/funder, who has granted bioRxiv a license to display the preprint in perpetuity. It is made available under aCC-BY-NC-ND 4.0 International license.

Table S2: The composition of ink formulations and their abbreviations: Tricyclo[5.2.1.02,6]decanedimethanol diacrylate (TCDMDA), Ethylene glycol dicyclopentenyl ether acrylate (EGDPEA), 2,2-Dimethoxy-2-phenylacetophenone (DMPA), (2,4-Diethyl-9H-thioxanthen-9-one(DETX), Ethyl 4-(dimethylamino)benzoate(EDB), neopentyl glycol diacrylate (NGPDA)

\begin{tabular}{|c|c|c|c|c|c|c|}
\hline \multirow{2}{*}{ Acronym } & \multicolumn{3}{|c|}{ Monomers } & \multicolumn{3}{|c|}{ Initiators } \\
\hline & TCDMDA & EGDPEA & NGPDA & DETX & EDB & DMPA \\
\hline TCDMDA-DETX-0.5 & $\sqrt{ }$ & -- & -- & $0.5 w t \%$ & $0.5 w t \%$ & -- \\
\hline TCDMDA-DETX-1 & $\sqrt{ }$ & -- & -- & $1 w t \%$ & $1 w t \%$ & -- \\
\hline TCDMDA-DETX-2 & $\sqrt{ }$ & -- & -- & $2 w t \%$ & $2 w t \%$ & -- \\
\hline TCDMDA-DETX-4 & $\sqrt{ }$ & -- & -- & $4 w t \%$ & $4 w t \%$ & -- \\
\hline TCDMDA-DMPA-0.5 & $\sqrt{ }$ & -- & -- & -- & -- & $0.5 w t \%$ \\
\hline TCDMDA-DMPA-1 & $\sqrt{ }$ & -- & -- & -- & -- & $1 w t \%$ \\
\hline TCDMDA-DMPA-2 & $\sqrt{ }$ & -- & -- & -- & -- & $2 w t \%$ \\
\hline TCDMDA-DMPA-4 & $\sqrt{ }$ & -- & -- & -- & -- & $4 w t \%$ \\
\hline EGDPEA-DETX-0.5 & -- & $\sqrt{ }$ & -- & $0.5 w t \%$ & $0.5 w t \%$ & -- \\
\hline EGDPEA-DETX-1 & -- & $\sqrt{ }$ & -- & $1 w t \%$ & $1 w t \%$ & -- \\
\hline EGDPEA-DETX-2 & -- & $\sqrt{ }$ & -- & $2 w t \%$ & $2 w t \%$ & -- \\
\hline EGDPEA-DETX-4 & -- & $\sqrt{ }$ & -- & $4 w t \%$ & $4 w t \%$ & -- \\
\hline EGDPEA-DMPA-0.5 & -- & $\sqrt{ }$ & -- & -- & -- & $0.5 w t \%$ \\
\hline EGDPEA-DMPA-1 & -- & $\sqrt{ }$ & -- & -- & -- & $1 w t \%$ \\
\hline EGDPEA-DMPA-2 & -- & $\sqrt{ }$ & -- & -- & -- & $2 w t \%$ \\
\hline EGDPEA-DMPA-4 & -- & $\sqrt{ }$ & -- & -- & -- & $4 w t \%$ \\
\hline NGPDA-DMPA-0.5 & -- & -- & $\sqrt{ }$ & -- & -- & $0.5 w t \%$ \\
\hline NGPDA-DMPA-1 & -- & -- & $\sqrt{ }$ & -- & -- & $1 w t \%$ \\
\hline NGPDA-DMPA-2 & -- & -- & $\sqrt{ }$ & -- & -- & $2 w t \%$ \\
\hline NGPDA-DMPA-4 & - & -- & $\sqrt{ }$ & -- & -- & $4 w t \%$ \\
\hline
\end{tabular}




\section{Correlation Analysis}

Statistical analysis was performed using GraphPad Prism 6: Pearson's correlation coefficient was introduced to quantify the correlation of the residual $\mathrm{C}=\mathrm{C}$ groups versus bacterial surface coverage, mammalian cell cytotoxicity and storage modulus of the printed polymeric structure.

$$
r=\frac{\sum_{i=1}^{n}\left(x_{i}-\bar{x}\right)\left(y_{i}-\bar{y}\right)}{\sqrt{\sum_{i=1}^{n}\left(x_{i}-\bar{x}\right)^{2}} \sqrt{\sum_{i=1}^{n}\left(y_{i}-\bar{y}\right)^{2}}}
$$

where $n$ is the sample size, $x_{i}$ and $y_{i}$ are the single data points, $\bar{x}$ and $\bar{y}$ are the mean value.
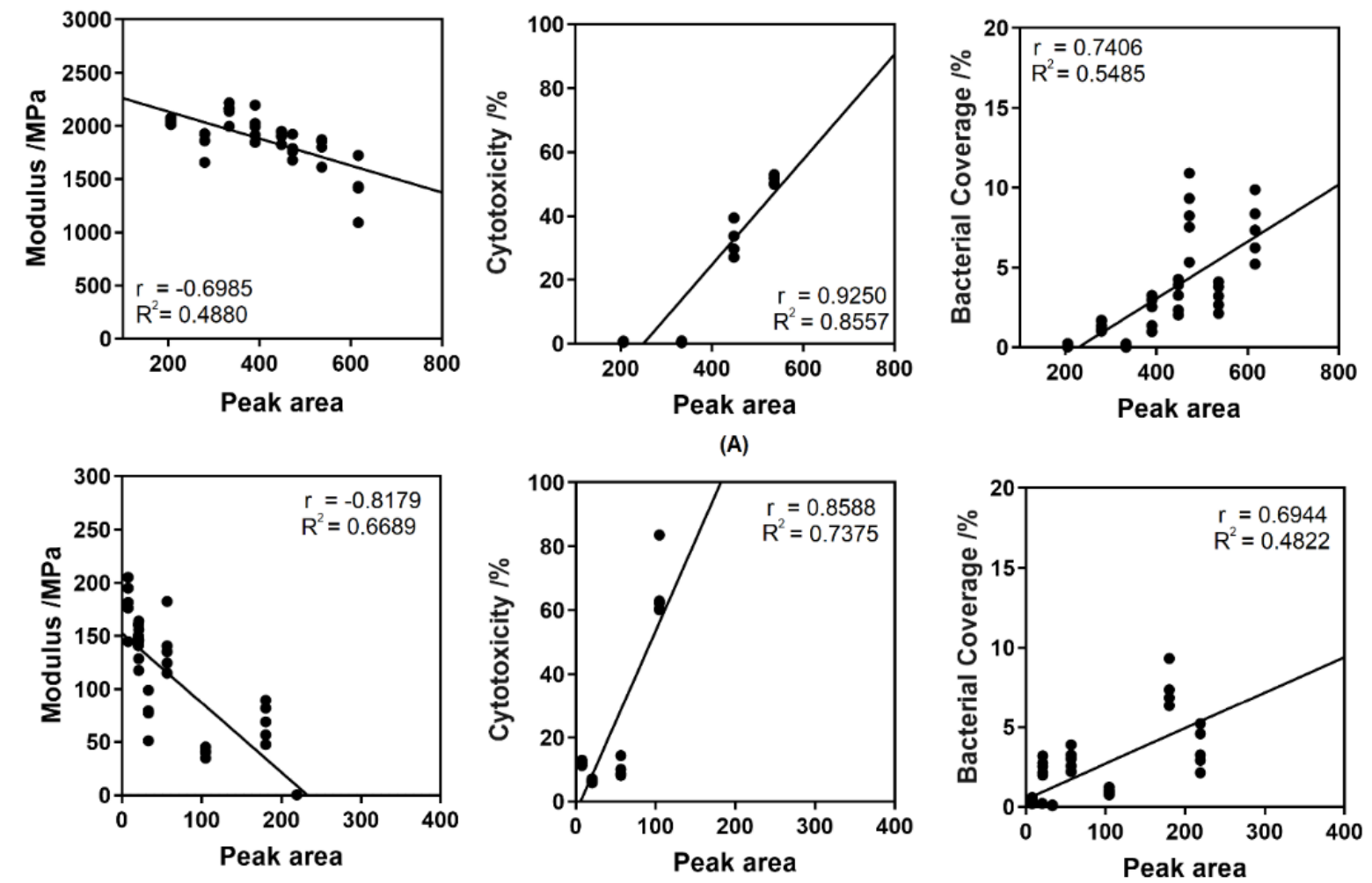

(B)

Fig. S1: Pearson's correlation analysis between the $\mathrm{C}=\mathrm{C}$ residual level and bacterial biofilm formation, cytotoxicity and storage modulus respectively. The residual monomer level was judged by the peak area of $\mathrm{C}-\mathrm{H}$ out-of-plate bending vibration on $\mathrm{C}=\mathrm{C}$ at $810 \mathrm{~cm}^{-1}$. (A) TCDMDA-DMPA. (B) EGDPEA-DMPA 


\section{Comparison of Specimens dimensions with CAD design}
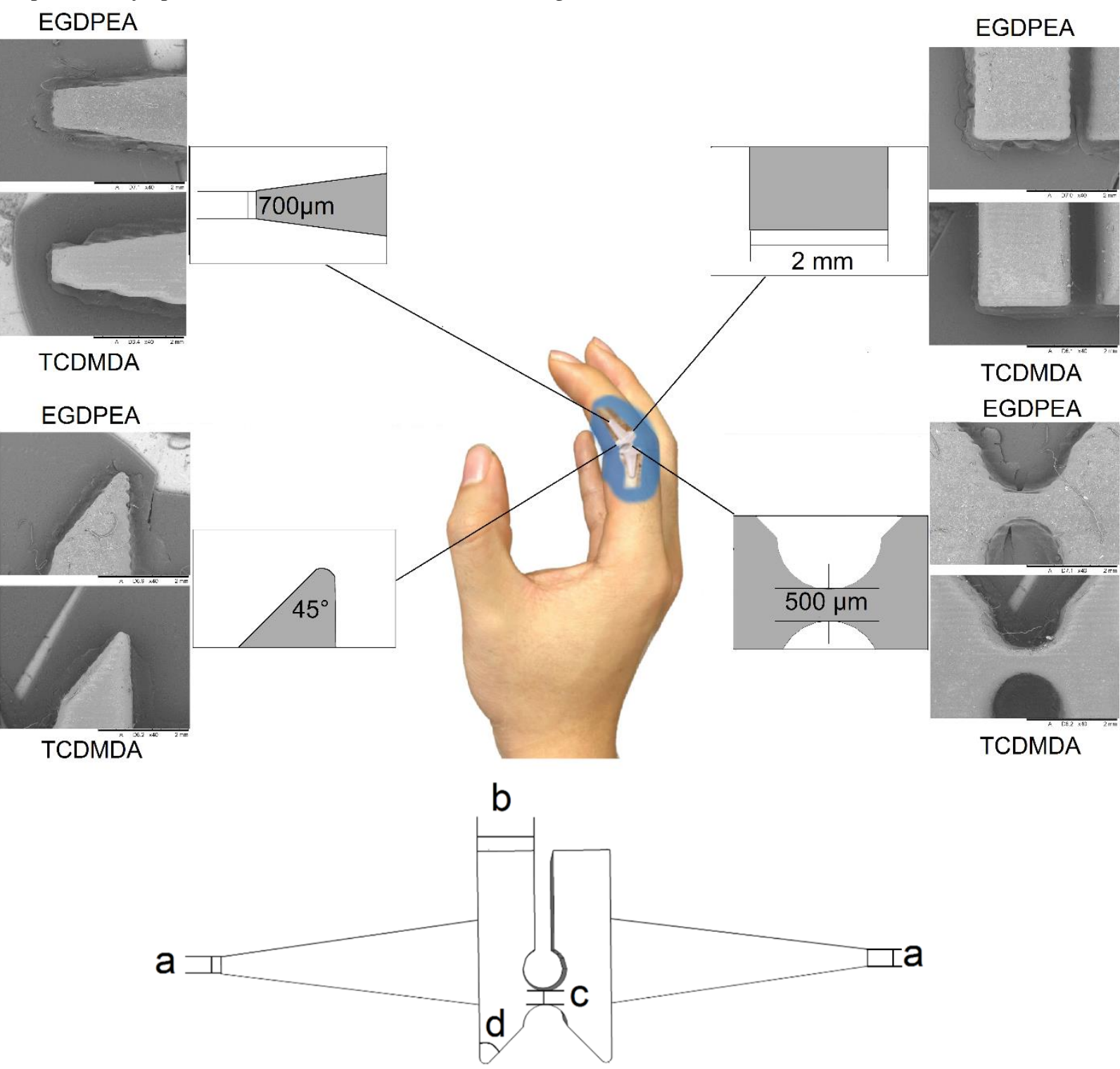

\begin{tabular}{cccc} 
& Design & EGPEDA & TCDMDA \\
\hline $\mathrm{a}$ & $700 \mu \mathrm{m}$ & $741 \mu \mathrm{m}$ & $710 \mu \mathrm{m}$ \\
$\mathrm{b}$ & $2000 \mu \mathrm{m}$ & $2104 \mu \mathrm{m}$ & $2054 \mu \mathrm{m}$ \\
$\mathrm{c}$ & $500 \mu \mathrm{m}$ & $544 \mu \mathrm{m}$ & $507 \mu \mathrm{m}$ \\
$\mathrm{d}$ & $45^{\circ}$ & $42^{\circ}$ & $44^{\circ}$ \\
\hline
\end{tabular}

Fig. S2: Comparision of the CAD designed feature size with the actual printed specimen size from 4 different key feature points $(\mathrm{a}-\mathrm{d})$. 


\section{Mammalian cell cytotoxicity}

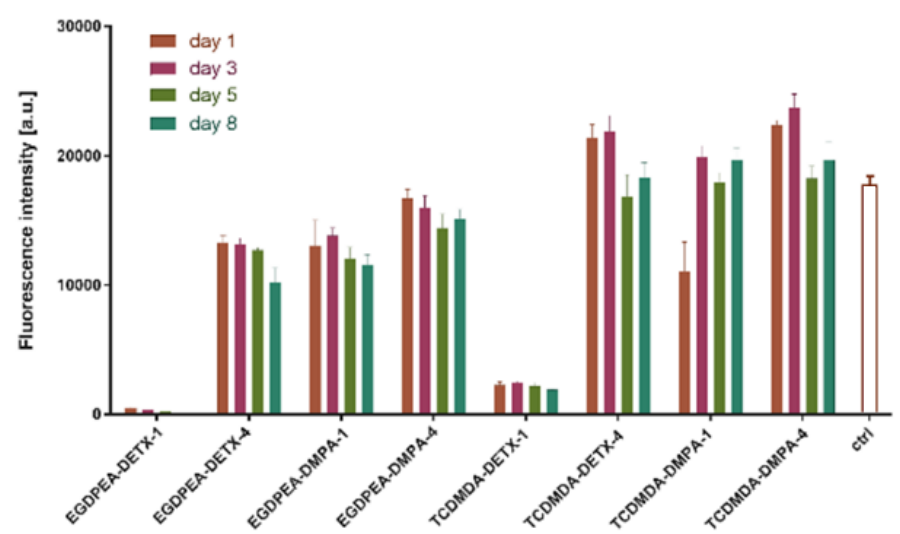

Fig. S3: Mammalian cytotoxicity assays using the Presto Blue ${ }^{\circledR}$ assay for printed TCDMDA and EGDPEA samples with both DMPA and DETX initiators at $1 \mathrm{wt} \%$ and $4 \mathrm{wt} \%$. The sampling time was 1, 3, 5 and 8 days. The data are presented are mean \pm standard deviation, $n=5(* \mathrm{p} \leq 0.05)$.

\section{Bacterial Viability test}

(A)

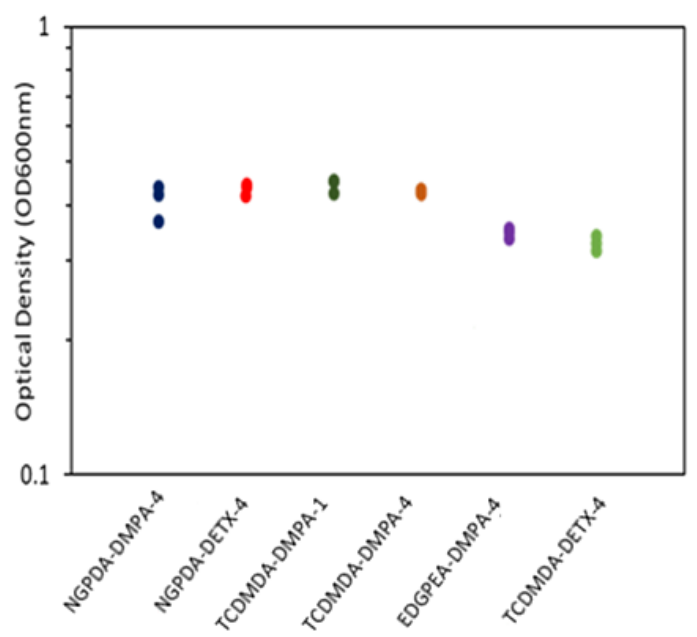

(B)

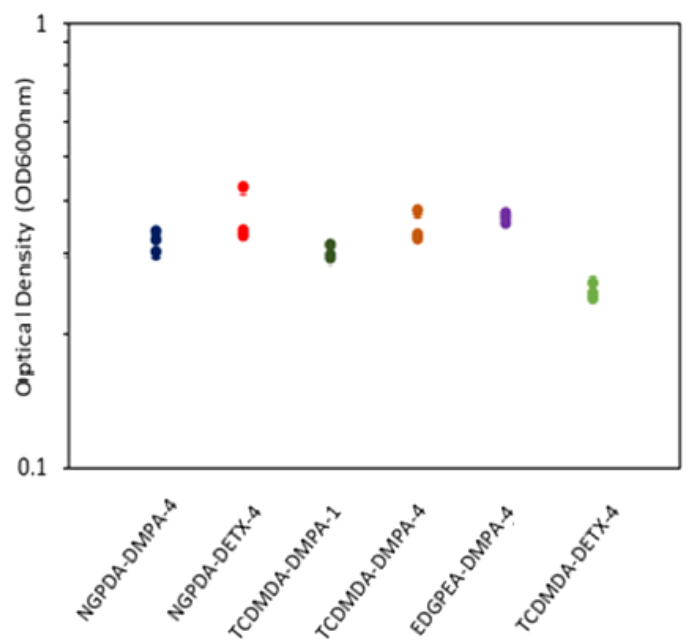

Fig. S4: Devices were printed with different ink formulations: NGPDA-DMPA-4, NGPDA-DETX-4, EDGPEADMPA-4, TCDMDA-DMPA-1, TCDMDA-DMPA-4, or TCDMDA-DETX-4. Samples were immersed in RPMI1460 medium inoculated with $P$. aeruginosa (A) or S. aureus (B) cells for $24 \mathrm{~h}$. The stationary phase OD600 reached for $P$. aeruginosa and $S$. aureus are shown in (A) and (B) respectively. Mean \pm Standard Deviation, $\mathrm{n}=3$. 
bioRxiv preprint doi: https://doi.org/10.1101/2020.06.30.180596; this version posted July 2, 2020. The copyright holder for this preprint (which was not certified by peer review) is the author/funder, who has granted bioRxiv a license to display the preprint in perpetuity. It is made available under aCC-BY-NC-ND 4.0 International license.

Bacterial and antibody marking of implant tested in vivo

A. Un-Infected

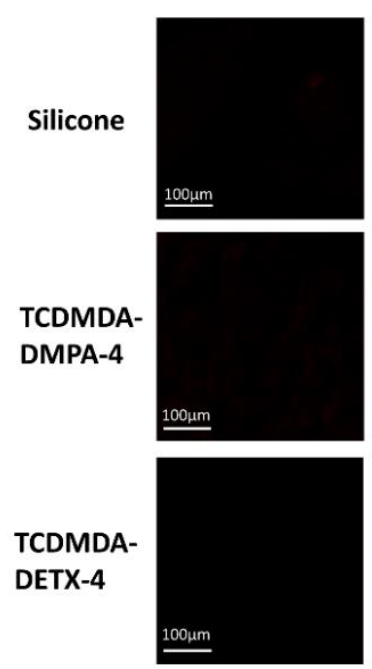

Antibody to P. aeruginosa
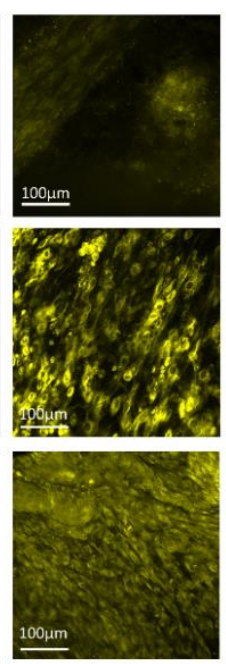

FM1-43
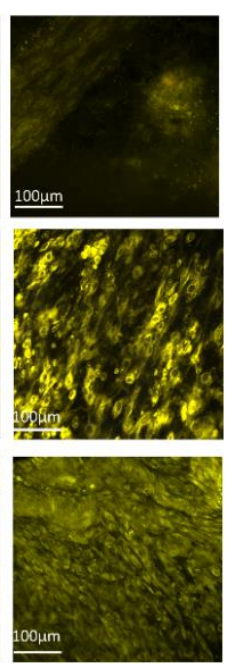

Co-localisation

Fig. S5. Immunohistochemistry of the TCDMDA and silicone implants $e x$ vivo showing the presence of bacteria and host cells. TCDMDA and silicone implants were recovered from (A) control, uninfected mice and (B) mice infected with $P$. aeruginosa. Implants were stained with an antibody to $P$. aeruginosa (red) and with the membrane stain FM1-43 (yellow). No bacteria were detected on the uninfected controls. On silicone, large numbers of individual whole bacterial cells and some bacterial aggregates are apparent. For both TCDMDA formulations but not silicone, there is a strong host response that co-localizes with bacterial cells and cell fragments. 